University of Rhode Island

DigitalCommons@URI

Open Access Dissertations

1989

\title{
LOCUS OF CONTROL: DEVELOPMENT OF PERCEIVED CONTINGENCY AND PERCEIVED COMPETENCE IN CHILDREN
}

Anthony Traniello

University of Rhode Island

Follow this and additional works at: https://digitalcommons.uri.edu/oa_diss

\section{Recommended Citation}

Traniello, Anthony, "LOCUS OF CONTROL: DEVELOPMENT OF PERCEIVED CONTINGENCY AND PERCEIVED COMPETENCE IN CHILDREN" (1989). Open Access Dissertations. Paper 1049.

https://digitalcommons.uri.edu/oa_diss/1049

This Dissertation is brought to you for free and open access by DigitalCommons@URI. It has been accepted for inclusion in Open Access Dissertations by an authorized administrator of DigitalCommons@URI. For more information, please contact digitalcommons-group@uri.edu. 


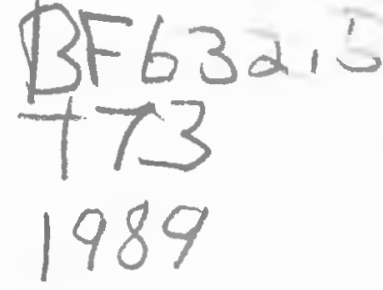

LOCUS OF CONTROL: DEVELOPMENT OF PERCEIVED CONTINGENCY AND PERCEIVED COMPETENCE IN CHILDREN

BY

ANTHONY TRANIELLO

A DISSERTATION SUBMITTED IN PARTIAL FULFILMENT OF THE REQUIREMENTS FOR THE DEGREE OF DOCTOR OF PHILOSOPHY

IN

PSYCHOLOGY

21833866
UNIVERSITY OF RHODE ISIJAND

1989 


\section{Abstract}

A two phase study is reported on the same 100 preschool and grade five children which investigates the relationship between age and locus of control. Phase 1 examined reliabilities and validities of the children's Locus of Control scale and a Piaget-type measure of chance conceptualization in consideration of evidence that the relationship between age and internal locus of control reflects two control relevant constructs, perceived competence and perceived contingency. The two scales were found to be reliable and valid. Results suggested a direct relationship between perceived competence and chronological age, and an inverse relationship between perceived contingency and chronological age. Phase 2 examined the developmental effects of perceived competence and perceived contingency on locus of control. Children were exposed to identical experimental procedures and were distinguished in terms of expectancies for success under skill and chance conditions. Results confirmed that grade five children respond to the skill versus chance dichotomy in ways predicted by Rotter's theory of locus of control. However, preschool children respond in ways predicted by Piaget's cognitive developmental theory. It was contended that cognitions about competence and contingency mediate between situational variables and performance. 
Acknowledgment

This work is dedicated to the memory of my father, Anthony Traniello Sr., DMD; and to my mother, Louise, and sister, Adele, for their unconditional support.

I am very grateful to my major professor, william Vosburgh, for liberal doses of sage wisdom and assured guidance. I extend thankfulness to the members of my committee, Dominic Valentino, and Anthony Allen for their interest and advice; and especially to Jerry cohen for his additional efforts in the methodological aspects of the research.

I also thank Janet Kulberg for helping me to formulate my ideas about the project when they were in their infancy. Gratitude is also due to Kathleen o'Rourke, Director of Pupil Personnel Services for the Public Schools of Hull, Massachusetts, for taking a special interest in the project, and to the teachers, pupils, and parents of Hull for their active participation. 


\section{Table of contents}

Page

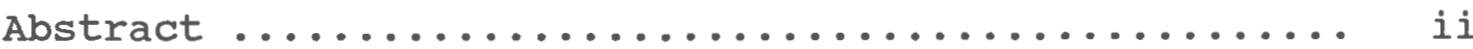

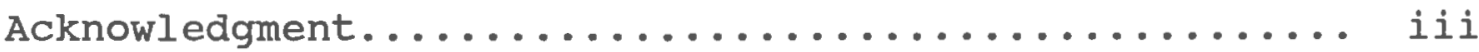

Table of Contents....................... iv

List of Tables......................... vii

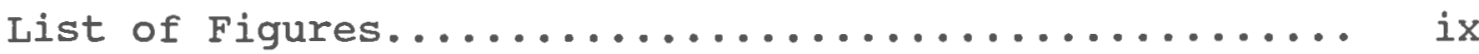

Introduction............................. 1

Studies with adults..................... 5

studies with children....................... 11

Statement of the Problem................. 18

Hypotheses............................ 19

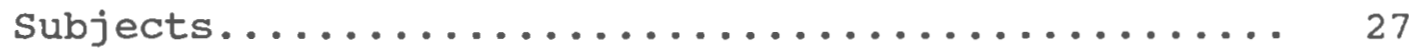

Phase 1: An Interview Validation Study.......... 31

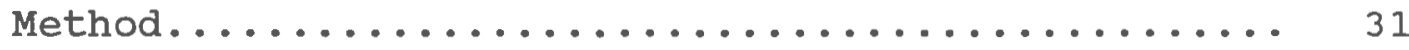

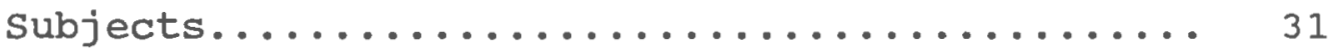

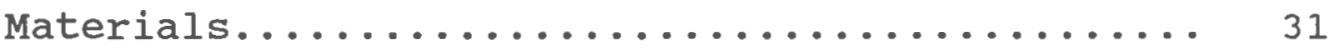

Bialer Locus of Control Questionnaire....... 32

Piaget-type Measure................. 33

Peabody Picture Vocabulary Test-Revised..... 34

Design............................... 36

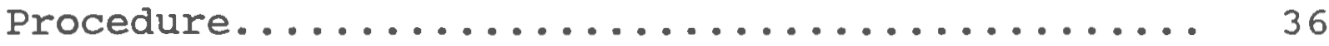

Bialer Locus of Control Questionnaire....... 36

Piaget-type Measure................ 36

Peabody Picture Vocabulary Test-Revised..... 38

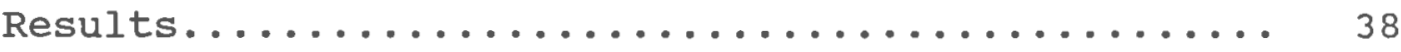

First hypothesis.................. 38 


\section{Table of contents (Continued)}

\section{Page}

Second hypothesis.................... 38

Phase 2: A Multifactor Repeated Measures Study....... 46

Method.............................. 46

subjects....................... 46

Materials....................... 46

Chance game...................... 46

skill game....................... 46

Procedure....................... 47

Chance game...................... 47

skill game...................... 48

Betting technique................. 49

Results........................... 50

Third hypothesis................... 60

Fourth hypothesis.................. 63

Fifth hypothesis................... 64

Sixth Hypothesis.................. 67

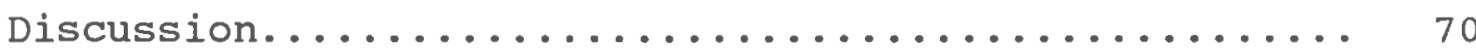

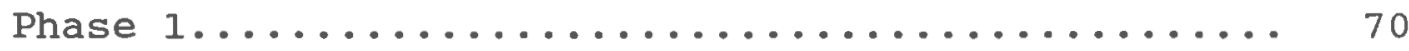

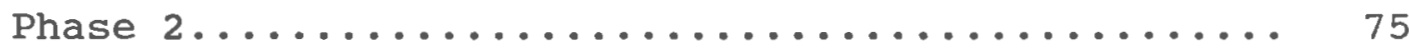

General discussion...................... 81

Future research........................ 85

References............................... 87

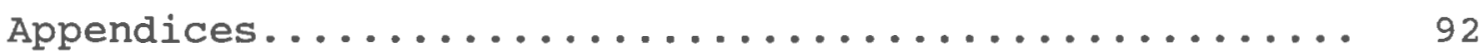

A. Bialer Locus of Control Questionnaire........ 92

B. Trajectory Drawing Form................ 94 


\section{Table of contents (Continued)}

Page

c. Scoring Criteria for Children on the Piagetian Game of Random Mixture and Reversibility........................ 95

D. Muller-Lyer Reference Design............... 96

E. Muller-Lyer stimulus Design............... 97

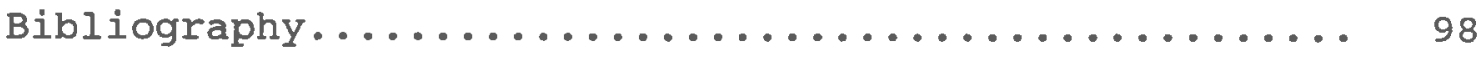




\section{List of Tables}

Page

Table 1 Chronological Ages of

subjects in Years..................

Table 2 Standard Scores of subjects

on the Peabody Picture Vocabulary

Test - Revised.

Table 3

Intercorrelations Between Chronological

Age, Verbal Ability and Locus of Control

Measures for Elementary School Children...

Table 4 Chronological Age, Verbal Ability

and Locus of Control Scores for

Elementary school Children............

Table 5 Stability Coefficients of the Bialer

and Piaget-type Measures ............

Table 6 Stability coefficients of the Bialer

and Piaget-type Measures for

Preschool Children..................

Table 7 stability coefficients of the Bialer

and Piaget-type Measures for Grade

Five children....................... 44

Table $8 \quad$ Summary of Analysis of Variance for

Expectancy Scores................... 51

Table 9 Expectancy Scores for Preschool Children

by Gender, Game, and Trial........... 52

Table 10 Expectancy Scores for Grade Five

Children by Gender, Game and Trial....... 


\section{List of Tables (Continued)}

Page

Table 11 Expectancy Scores of Elementary School

Children by Grade.

Table 12 Expectancy Scores of Elementary School

Children by Game.................... 56

Table 13 Expectancy Scores of Elementary School

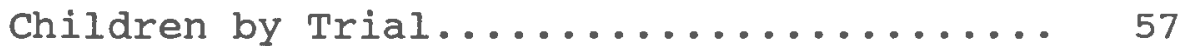

Table 14 Expectancy Scores for Elementary School

Children by Game and Trial............ 58

Table 15 Expectancy Scores for Elementary school

Children by Grade, Game and Trial....... 59 


\section{List of Figures}

Page

Figure 1 Mean Expectancy Scores for

Grade Five Children for

Skill and Chance Games ............. 61

Figure 2 Mean Expectancy Scores for

Preschool Children for

Skill and Chance Games............... 62

Figure 3 Mean Expectancy Scores for Grade Five

and Preschool Children for

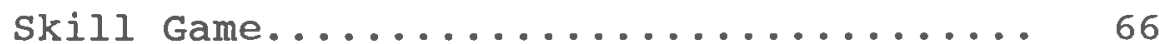

Figure 4 Mean Expectancy Scores for Grade Five

and Preschool Children for

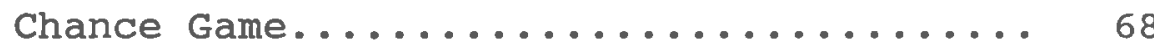




\section{Introduction}

Theories of cognitive development may be contrasted on the issue of whether development is best described as a continuous process without marked behavioral reorganization or a step-by-step progression through a regular series of stages, each of which is distinguished by a particular behavioral structure.

Structuralist theorists (Flavell, 1963; Piaget \& Inhelder, 1975) contend that cognitive development moves through systematic and invariant stages. Each stage is defined by observable cognitive attributes and every consecutive stage in the sequence represents a reorganization of earlier stages into a functional totality which is qualitatively different from its antecedent.

Connectionist and reinforcement theorists (Hull, 1952; Skinner, 1953) maintain that cognitive development is a continuous, additive consequence of differential environmental reinforcement. Maturity is represented by the gradual association of specific acts in response to environmental contingencies.

Social learning theorists (Bandura, Adams, \& Beyer, 1977; Bandura \& Walters, 1963; Rotter, 1982) concur with the connectionist view that the learning process is qualitatively similar at every point along the developmental continuum, however, they focus on the reciprocal relationship between the processes of cognition and information derived from the environment. Although 
social learning theorists preserve connectionist variables of cue, response, and reinforcement, they also maintain that structuralist constructs cannot be dismissed easily. This is because they assert that stimulus and reinforcement contingencies produce an inappreciable impact on behavior unless they are first represented mentally. Specifically, social learning theorists depart from the strict determinism associated with a connectionist view in so far as they propose that mediational variables permit children to be active participants in their own development with respect to internal regulation and control of behavior. As a social learning theorist, Rotter (1975) endeavors to integrate connectionist and structuralist approaches to understanding human behavior. Rotter establishes an explicit relationship to connectionist psychology with his analogous concepts of expectancy, behavior potential, reinforcement, and psychological situation.

on a descriptive level, these concepts approximate Hull's (1943) system of behavior which involves reaction potential, habit strength, drive, and independent variable--both formulations refer to learning (expectancy and habit strength), to response tendencies (behavior potential and reaction potential), to motivation (value of reinforcement and drive), and to controlling stimulus cues (psychological situation and independent variables).

Rotter's (1982) constructs are related in the following way: predictions of the potential for a 
particular behavior to occur require evaluation of the perceived expectancy that a given behavior will be successful, consideration of the value of the available reinforcement to the individual, and specification of the stimulus cues which constitute the psychological situation. Behavior at the complex human level is explained as a matter of selection for the individual, and selection is a function of expectancy, value of reinforcement, and psychological situation.

Rotter's construct of expectancy developed out of his social learning theory as an intervening variable which makes possible more reliable predictions about how reinforcement changes human social behavior (James \& Rotter, 1958). Expectancy influences how reinforcement will be interpreted by the individual. For example, once a person establishes an expectancy that reinforcement is either random or systematic, the effects of reinforcement will vary depending upon how the behavior-outcome relationship is characterized (Rotter, 1966).

The construct, locus of control, operationalizes the mediating variable, expectancy, in the role of reinforcement. More specifically, locus of control refers to the perceived expectation for internal versus external control of reinforcement. Internal control signifies the expectation that rewards or punishments will be dependent upon one's own actions. External control signifies the expectation that reinforcement will be independent of one's 
own actions because of chance, powerful others, or complex systems (Rotter, 1966, 1975).

Rotter (1966) expressly defined the relationship between locus of control and reinforcement in the following way:

If a person perceives a reinforcement as contingent upon his [sic] own behavior, then the occurrence of either a positive or a negative reinforcement will strengthen or weaken potential for that behavior to recur in the same or similar situation. If he [sic] sees the reinforcement as being outside his [sic] own control or not contingent, that is depending upon chance, fate, powerful others, or unpredictable, then the preceding behavior is less likely to be strengthened or weakened. (p. 5) Once more, the effect of a reinforcement depends, in part, on an individual's perception about the nature of the causal relationship between response and outcome. In order to test this relationship, Rotter (1966) postulated that locus of control could be manipulated by presenting subjects with cues associated with skill and chance situations.

Internal control is induced in subjects when a situation is structured in such a way that outcomes are perceived as dependent upon responses (skill cues). Under these conditions, a strong, direct relationship is predicted between changes in outcome variables and response 
measures. Given a sequence of trials on some performance task, human subjects will show an increase in expectancy for success on the following trial subsequent to positive reinforcement and a decrease in expectancy for success on the following trial in the absence of reinforcement.

on the other hand, external control is induced in subjects when a situation is structured in such a way that outcomes are perceived as independent of response (chance cues). Under these conditions, Rotter predicted a weak and variable relationship between changes on outcome variables and response measures. Also, when presented with chance cues, Rotter predicted that subjects are likely to show more unusual shifts in behavior, which he operationally defined as "a raise in expectancy following negative reinforcement or a decrease in expectancy following positive reinforcement" (James \& Rotter, 1958, p. 398).

In summary, for a subject to consistently change behavior in response to outcome, the relationship between response and outcome must be perceived as internally controlled, that is, dependent or contingent on one's own actions, although the objective reality of the relationship may be externally controlled, that is, actually random or experimentally manipulated.

Choice of task: Studies with adults

Phares (1957) performed the first in a series of inquiries using adult volunteers to show that locus of control could be manipulated by the introduction of skill 
and chance cues. He presented undergraduate students with color and line matching tasks which varied according to skill and chance instructions. Phares controlled a fixed pattern of reinforcement and applied a betting technique as the response measure of perceived control. On each acquisition trial, he asked his subjects to wager from 1 to 10 chips on their probability of success for the following trial. Subjects received positive reinforcement by winning chips bet on correct trials. No reinforcement was provided on incorrect trials.

As predicted by Rotter's hypothesis of locus of control, Phares' (1957) subjects behaved differently when exposed to skill and chance cues. Greater changes of expectations in the direction of past performance, that is usual shifts, were established when outcomes were perceived to be dependent on responses (contingent or skill condition) than when outcomes were perceived to be independent of responses (random or chance condition). The results for unusual shifts were not significant. Phares concluded that a situational analysis of expectancy changes using the skill versus chance dichotomy was feasible.

In an ensuing study, Phares (1962) introduced skill and chance cues to measure recognition thresholds of adult volunteers to a tachistoscopic display of nonsense syllables under conditions of negative reinforcement. Visual symbols were paired with shock reinforcement, which was terminated when the subject pressed the correct control 
button. Subjects in the skill situation were run first, and subjects in the chance situation were matched for pattern of reinforcement (escape from shock).

Subjects who were exposed to shock under skill instructions were found to be significantly more alert, that is, showed smaller recognition thresholds for shock associated stimuli, than subjects who were given shock under chance instructions. Phares (1962) determined that adults learn more quickly under conditions where skill cues influence them to interpret reinforcements as contingent on personal attributes of competence or ability (internal control) than under conditions where chance cues imply noncontingency or unpredictability (external control). The effect of the skill versus chance dichotomy on locus of control in adults was demonstrated in subsequent experiments by Rotter and his associates (James \& Rotter, 1958; Rotter, Liverant, \& Crowne, 1961).

James and Rotter (1958) investigated acquisition and extinction of verbalized expectancies for success in undergraduate student volunteers given skill and chance instructions for a card guessing task. Expectancy for success was operationally defined as the probability verbalized by subjects on a scale from 0 to 10 (highest) that a particular reinforcement would occur in a specific situation. Responses to training schedules of $50 \%$ random reinforcement and $100 \%$ reinforcement were measured.

James and Rotter (1958) obtained mixed results using 
verbalized expectancy statements as a response measure. They established no significant difference between skill and chance cues under acquisition; however, some differences were obtained under extinction. James and Rotter maintained that their findings were sufficient to conclude that perceived expectancy acts as an intervening variable in complex human learning; and by implication, that this variable could be studied using the skill versus chance dichotomy.

In a succeeding study, in which instructions were held constant but tasks were varied according to intrinsic cues, Rotter, Liverant, and Crowne (1961) tested the prediction that subjects will learn more from the occurrence of a reinforcement when they perceive outcome on a task to be dependent on response (contingent or internally controlled), than when outcome is perceived to be independent of response (random or externally controlled).

Rotter et al. (1961) manipulated locus of control by asking undergraduate student volunteers to participate in two tasks, one of which required raising a platform without allowing a ball to fall off it (skill) and the other of which involved a card guessing game (chance). For each training schedule of $25 \%, 50 \%, 75 \%$, and $100 \%$ reinforcement, the investigators controlled a fixed pattern of reinforcement by using experimenter-provided feedback about success. Subjects' verbal estimates about the likelihood of success on the subsequent trial (ranging from a low of 0 
to a high of 10) were used again as the response measure of expectancy.

In this experiment, Rotter et al. (1961) found a significant interaction between contingency cues and reinforcement schedules under training conditions. Subjects in the skill situations verbalized a greater expectancy for success in the direction of previous reinforcement than subjects in the chance situations at $25 \%$ and $50 \%$ reinforcement. However, the difference was not significant between skill and chance groups at $50 \%$ and $100 \%$ reinforcement. The apparent interaction suggested to the investigators that pattern of reinforcement may be a cue in its own right which influences subjects' perceptions of locus of control.

In some more contemporary inquiries, Langer (1975) and Langer and Roth (1975) verified that sequence of reinforcement influences expectancy. Langer showed that adults behave as though objectively chance events are controlled internally when the events are occasioned by a descending sequence of reinforcement, and a range of other skill cues such as choice, stimulus or response familiarity, passive or active involvement, and competition. Langer (1975) labelled this overestimate of personal control, which occurs in random situations occasioned by skill cues, as illusory control. She operationally defined illusory control as "an expectancy of a personal success probability inappropriately higher than 
the objective probability would warrant" (p. 311).

In a laboratory investigation, Langer and Roth (1975) brought about illusory control by manipulating the sequence of reinforcement. Undergraduate volunteers were asked to predict outcomes for themselves or others on 30 coin tosses. Subsequently, subjects received feedback about their success according to one of three experimenter controlled reinforcement schedules: a descending series in which success feedback was concentrated toward the starting trials, an ascending series in which success feedback was concentrated toward the finishing trials, and a random series. Response measures included a questionnaire designed to evaluate if subjects perceived the task as chance- or skill-determined and questions estimating success in the past and future.

Langer and Roth (1975) determined that an early series of reinforcement, the descending condition, was associated with a skill orientation and an illusion of personal control. Also, people who were directly involved in prediction rated themselves higher than they rated others. Langer and Roth concluded that early reinforcement and an opportunity for involvement are salient factors which induce an illusion of control over apparently chance determined events even in sophisticated adult subjects.

In a series of field studies Langer (1975) investigated other skill cues which induce a perception of exaggerated personal control. Choice was examined by 
giving some adult subjects a lottery ticket and allowing others to select one. Stimulus familiarity was varied by using tickets printed with letters of the alphabet versus line drawings of novel symbols. Practice was provided to induce response familiarity. In a passive involvement condition, an examiner manipulated the apparatus. In an active involvement situation, the subject moved a stylus. Competition was investigated by asking subjects to participate in a card game against a confederate who appeared confident or nervous.

Langer (1975) established that the presentation of skill cues into objectively random events, in a variety of situations as specified above, significantly increased the likelihood that adult subjects would interpret and react to these events as if they were personally controllable. The power of this expectancy effect on subjects was demonstrated by their verbal predictions of greater success on future trials in the skill than in the chance situations.

Choice of task: studies with children

The above studies dealt exclusively with sophisticated adult volunteers, most often with available samples of undergraduate students in psychology. There is doubt that generalizations from these restricted samples to a child population can be assumed to be valid (Rosenthal \& Rosnow, 1975). Mention of them is made to describe the variables which have been used to investigate locus of control and to 
point out the need for research in locus of control where it is developmentally significant, namely among children.

Consistent with connectionist and social learning theory, some researchers propose that locus of control is related to age in a continuous and direct manner. Investigators at the Fel's Research Institute (Crandall, Katkovsky, \& Crandall, 1965) hypothesized that early in development, children perceive the world as externally controlled because of their dependence upon powerful others for instrumental help. According to this explanation, expectancies for internal control gradually increase, in an additive way, as children learn to associate success in attaining rewards with their own actions.

In order to explore relations between children's reinforcement beliefs and age, measured by grade level, Crandall et al. (1965) developed the Intellectual Achievement Responsibility Questionnaire (IAR). This is a 34 item forced-choice scale constructed to measure children's judgments about responsibility in achievement situations. However, using this measure with an extensive sample of 923 elementary- and high-school students in grades 3 through 12, Crandall et al. (1965) failed to find a significant increase in internality related to age.

In a comprehensive review of the literature pertaining to locus of control, Lefcourt (1982) concurred with the observation that variables associated with age are likely sources of change in the perception of internal control. 
However, Lefcourt pointed out that divergent opinions exist concerning essential aspects of the relationship.

specifically, Lefcourt alluded to some evidence in studies by Penk (1969) and Bialer (1961) which revealed a direct relationship between age and internal control, and contrary evidence found in studies by Weisz and Stipek (1982) which indicated an inverse relationship between these variables.

Penk (1969) examined age and internal locus of control by means of the Children's Locus of Control Questionnaire (Bialer, 1961), a 23 item "yes" or "no" scale for children which is scored in the direction of internal control. The questionnaire was one of nine experimental tasks including the Peabody Picture Vocabulary Test (Dunn, 1959) which Penk administered to five groups of children ranging in ages from 7 to 11 years old. Subjects were of average intelligence from middle-class families and attended parochial school.

Penk (1969) hypothesized that age and internal control are directly related based on the essential construct of competence. Specifically, Penk predicted that associated with increasing mastery, measured by the receptive language score on the Peabody Picture Vocabulary Test, there will be an attendant increase in a child's understanding that outcomes are under personal control, measured by the internal locus of control score on Bialer's scale.

Penk (1969) established a low but significant positive 
correlation between chronological age and internal control as evaluated by the Children's Locus of control Scale ( $\underline{r}=$ .27). A comparable positive intercorrelation was obtained between mental age on the Peabody Picture Vocabulary Test and internal control on the Bialer Scale $(\underline{r}=.26)$. Penk concluded that the pattern of correlations was sufficient to demonstrate a direct relationship between mastery, measured by receptive vocabulary, and internal locus of control in children.

Lefcourt (1982) noted that the study by Penk (1969) replicated an earlier report by Bialer (1961) in which a higher correlation was obtained between chronological age and internal control ( $\underline{r}=.37)$, measured by the Children's Locus of Control Questionnaire. However, Bialer established an even stronger correlation between mental age, measured by the Peabody Picture Vocabulary Test (Dunn, 1959), and internal locus of control by partialling out chronological age $(\underline{r}=.56)$.

Among other relationships, Bialer (1961) examined developmental change in internal locus of control in a combined group of cognitively delayed and average children of both sexes. Children ranged from a chronological age of 6-3 to 14-3 years, and from a mental age of 3-10 to 15-9 years. Forty-five intellectually delayed children were selected from special education classes and 44 average children were drawn from regular classes in public schools. All subjects were administered several experimental tasks 
in addition to the Peabody Picture Vocabulary Test (Dunn, 1959).

As postulated by Bialer (1961), results of the study indicated that mental age, rather than chronological age, was the more relevant variable related to the inclination among children to perceive internal locus of control. Bialer substantially increased the range and variability of mental age compared to chronological age in his sample by including cognitively delayed children. Consequently, when Bialer partialled out mental age, chronological age carried no significant weight in prediction of locus of control.

In a reexamination of the studies by Bialer (1961) and Penk (1969), Weisz and Stipek (1982) proposed an alternative interpretation of their results. These researchers (Weisz \& Stipek, 1982) postulated that developmental increases in internal control obtained by Bialer (1961) and Penk (1969) confused two logically independent dimensions of locus of control, perceived contingency and perceived competence. Weisz and stipek (1982) defined perceived contingency as "the perceived responsiveness of the outcome to variations in the actor's behavior" (p. 262), and perceived competence as "the actor's self-assesed capacity to produce outcomes" ( $p$. 262).

Perceived contingency refers to whether or not a causal relationship is subjectively comprehended to exist between outcome and response. Perceived competence refers 
to what one believes one can do given the character of the causal relationship and optimal effort.

Weisz and Stipek (1982) concurred with the view that perceived competence is likely to increase with maturation as the child achieves actual mastery of the environment, but they contended that perceived contingency is likely to decrease with maturation as the child is introduced to the reality of a wide range of externally controlled events.

Weisz and stipek relied on the cognitive explanation of development formulated by Piaget (Flavell, 1963; Piaget \& Inhelder, 1975) for support of their hypothesis that perceived contingency is inversely related to age.

In studies of the development of causal attribution in children, Piaget (Flavell, 1963) determined that an infant interprets causality by understanding that all outcomes are linked to, and caused by, internal stimuli. The infant in sensorimotor stage misconstrues that internal events (indefinite feelings of effort and temporal contiguity) are responsible for external happenings.

Piaget (Flavell, 1963) observed that accurate perceptions of causal relationships by children begin to develop in the preoperational period from about age 3 or 4 to age 7. In part, as a consequence of increased social interaction, children's causal attributions begin to change from the egocentrism of the infant to the differentiated psychological and physical causality of the socialized adult. Children below the age of about 11 to 12 years 
(when formal operational thought develops) are consequently not expected to be able to respond maturely to chance events. Applying Piagetian theory, one would predict that younger children will overestimate perceived contingency more than older children.

In an effort to investigate a cognitive-developmental hypothesis of perceived contingency, Weisz (1980) studied children's judgments about chance outcomes in a card guessing game. Kindergarten and fourth grade children drew cards blindly from a shuffled deck to select colored spots and then predicted the winnings of other children. Response measures were coded answers to unstructured contingency questions and difference scores for predicted winnings of chips on paired comparison questions covering skill related content areas.

Weisz (1980) found that kindergarten children were more likely than fourth grade children to exaggerate contingency in apparently random situations. In a chancecontrolled children's game, kindergarten children were shown to be more strongly influenced than fourth graders by competence related cues of age, practice, ability, and effort. Weisz concluded that illusory contingency is inversely related to maturation although even fourth graders believed that competence related cues were somewhat related to outcomes.

Weisz (1981) replicated this evidence in a field study of children's contingency judgments performed at a state 
fair. Investigators surveyed two groups of children, a younger group (mean age of 8 years and 8 months) and an older group (mean age of 12 years and 1 month) after the children had played one of four randomly selected chance games. Response measures were similar to those employed in the previous experiment, which included answers to unstructured contingency questions and predicted winnings of other children based on grade level, ability, effort, and practice.

Weisz (1981) confirmed his previous findings that the overestimation of contingency by children is inversely related to age. Younger children rarely attributed chance outcomes of their own responses to random factors whereas older children often explained chance outcomes in terms of luck. Also, younger children expected significantly higher levels of success on chance tasks for players who were older, who were brighter, who were more experienced, and who tried harder. Consistent with Piagetian theory, the salience of illusory contingency was shown to diminish somewhat by adolescence.

statement of the problem

Based on the studies presented above, there is conflicting and inconclusive evidence about the relationship between internal locus of control and maturation. The present study assesses this relationship in an elementary school population using different operations and methods to test six hypotheses. Phase 1 is 
an interview validation study which tests the first two hypotheses, and Phase 2 is a multifactor repeated measures study which tests the remaining four hypotheses.

\section{Derivation of the hypotheses}

Phase 1 is, in part, an independent replication of the procedures used by Bialer (1961) and Penk (1969) to investigate the relationship between competence-based internal locus of control and age across a wider range of grade levels, operations, and methods than were previously explored. In accordance with the results of Bialer and Penk, the first hypothesis is stated formally as:

First Hypothesis. The perceived competence dimension of internal locus of control is directly related to age in children.

Prediction. Older children, defined by chronological age and mental age equivalent measured by the Peabody Picture Vocabulary Test - Revised (Dunn, 1981), will respond more frequently in the perceived competence direction, measured by the Children's Locus of Control Questionnaire (Bialer, 1961), than younger children defined as above.

The second major hypothesis of Phase 1 is concerned with the inverse relationship between contingency-based internal of locus of control and age found in studies by Weisz (1980, 1981) and Weisz and Stipek (1982). As indicated above, these investigators relied on a Piagetian explanation of chance conceptualization (Flavell, 1963; 
Piaget \& Inhelder, 1975) for a theoretical framework, although they did not specifically utilize Piagetian methods in their studies.

In the present investigation, a Piagetian procedure for examining chance conceptualization was adapted to operationalize the perceived contingency dimension of internal locus of control. It was considered that the construct validity of perceived contingency could be enhanced by replicating the work of Weisz and Stipek using operations developed by Piaget. In accordance with the results of Weisz and stipek, the second hypothesis is stated formally as:

second Hypothesis. The perceived contingency dimension of locus of control is inversely related to age in children.

prediction. Younger children, defined by chronological age and mental age equivalent measured by the Peabody Picture Vocabulary Test - Revised (Dunn, 1981), will respond more frequently in the perceived contingency direction, measured by the Piaget-type measure of chance conceptualization, than older children defined as above.

In addition to substantive issues, Phase 1 examines the psychometric properties of the Children's Locus of Control Questionnaire (Bialer, 1961) and the Piaget-type measure of chance conceptualization. It is important to determine the power and the limitations of both measures for use with young children. Specifically, internal 
consistency and retest reliabilities for the Bialer scale are analyzed along with retest and scorer reliabilities for the Piaget-type measure.

Phase 2 of this study is an extension of experiments by Rotter (James \& Rotter, 1958; Rotter, Liverant, \& Crowne, 1961) and his associates (James, 1957; Phares, 1957, 1962) which tested the effects of skill and chance variables on locus of control in adults. The experiment uses systematic manipulation of skill and chance variables to assess developmental differences in locus of control in a simultaneous study of preschool and grade five children. Betting behavior in response to reinforcement is used to operationalize expectancies for success. The larger the bet, on a scale from one to ten chips, the greater the expectancy for success.

In review, Rotter's (1966, 1975) social learning theory specifies that people behave differently in situations where reinforcement is understood to depend upon skill as opposed to chance factors. Rotter speculated that under skill conditions or cues, adults are likely to conclude that a series of reinforced trials are produced by internal factors such as ability or competence.

Under skill conditions, people use prior reinforcement as a basis for generalization to future reinforcement. Since the individual is the effective agent in a skill situation, one may logically generalize from past similar experiences. If one succeeds on a given trial, there 
should be an accumulative increment in expectancy for future success because scores are a function of competency. on the other hand, if one fails on a given trial, there should be a decrement in expectancy of future success.

Rotter (James \& Rotter, 1958) labeled responses of this type, which are in the direction predicted by his locus of control hypothesis, as usual shifts. In an experimental study of female college students, Phares (1957) found evidence that usual shifts are, in fact, more frequent in a situation categorized by subjects as skill.

Under chance conditions or cues, Rotter (James \& Rotter, 1958) reasoned that adults are likely to understand during acquisition that a series of reinforced trials are brought about by external factors such as luck. Nevertheless, adults perceive reinforcement as providing some basis for generalization to future performance. They are likely to base their expectancy for reinforcement upon incorrect reasoning such as a series of reinforced trials will decrease the probability that a reinforcement is likely. Rotter identified this phenomenon as the gambler's fallacy, and he labeled the increments in expectancy following failure and the decrements in expectancy following success as unusual shifts.

Rotter and his associates did not look into developmental aspects of locus of control. However, application of Piaget's (Piaget \& Inhelder, 1975) theory of cognitive development to the skill versus chance dichotomy 
suggests that, when formal operational thought emerges at about 11 to 12 years of age, children are likely to respond to the skill and chance dichotomy in ways which are predicted by Rotter's theory of locus of control for adults.

According to Piaget and Inhelder (1975), children at the stage of formal operations understand chance and random mixture based on an intuitive grasp of permutations, that is, the return of elements in a random mixture to an original configuration is considered possible but very improbable given a large number of events. If 11 to 12 year old children have a mature idea of chance, it is likely that they will show an adult pattern of responses to manipulation of skill and chance variables.

stemming from these findings, the third and fourth hypotheses are stated as follows:

Third Hypothesis. Children, at a formal operations stage of cognitive development, conclude that a series of reinforced trials under skill conditions are produced by the internal control factor of competence.

Prediction. Under skill conditions, defined by game, children in the formal operations group, defined by grade, will show a pattern of marked (significant) usual expectancy shifts in response to reinforcement, that is, increments after success and decrements after failure, in a series of trials measured by the number of chips bet per trial. 
Fourth Hypothesis. Children, at a formal operations stage of cognitive development conclude that a series of reinforced trials under chance conditions are produced by the external control factor of luck.

Prediction. Under chance conditions, defined by game, children in the formal operations group, defined by grade, will show a pattern of marked (significant) unusual expectancy shifts in response to reinforcement, that is, decrements after success and increments after failure, in a series of trials measured by number of chips bet per trial.

In regard to younger children, Piaget and Inhelder (1975) maintained that preoperational children, at about 4 to 7 years of age, interpret that random elements are somehow linked in a systematic way. Lacking an internalized standard of randomness or irreversibility, preoperational children impose order on many chance situations.

If a mature sense of chance results in a pattern of relatively marked expectancy shifts, that is, significant increments and decrements of betting in response to reinforcement; it is logical to conclude that an immature sense of chance will result in a pattern of expectancy shifts which is relatively stable or uniform. Thus, preoperational children are expected not to use outcome feedback accumulatively in response to either skill or chance conditions. The resulting pattern of uniform responses is not predicted by Rotter's social learning 
theory as it applies to adults.

Also, because preoperational children regard perceived contingency as the prominent feature of both skill and chance situations; the average expectancy for 4 to 7 year old children, measured by the magnitude of each bet, should exceed the average expectancy shown by 11 to 12 year old children in the comparable comparison group.

The rationale for this behavior was explicated by Weisz (1981) who found, in a field study of children's contingency judgments, that young children predicted certain baselines of success for outcomes under conditions of skill and chance. Weisz speculated that younger children make larger bets because they may expect to win at least certain minimal amounts, in effect, imposing subjective order (contingency) on both random and ordered situations.

In conclusion, preoperational children have a stronger sense of perceived contingency which is explained by baseline reasoning across both skill and chance situations. The consequence of this floor effect is a relatively higher and more uniform rate of responding (higher and more stable expectancy for success) for preoperational children compared to formal operations children in both skill and chance situations.

on the other hand, when expectancy for success (betting) is compared across skill and chance games for preoperational children, higher expectancy (larger bets) 
are predicted in the skill game because contingency cues should be even more prominent than in the chance game. This result is important, in part, in order to show that preoperational children differentiate between the games. It also signifies that, although changes in betting from trial to trial may be relatively small in response to reinforcement, preoperational children understand that success is more likely to be associated with skill than chance cues.

This process of reasoning leads to the last two hypotheses, which are formally stated as:

Fifth Hypothesis. Children, at a preoperational stage of cognitive development, impose subjective order or contingency on both skill and chance situations.

Prediction 1. Under skill and chance conditions, defined by game, children in the preoperational group, defined by grade, will show a pattern of uniform (insignificant) expectancy shifts in response to reinforcement in a series of trials measured by chips bet per trial. These children are expected not to use outcome feedback accumulatively in forming expectancies.

Prediction 2. Under skill and chance conditions, defined by game, children in the preoperational group defined by grade, will show a higher overall expectancy for success, measured by the total number of chips bet per game, than children in the formal operations group, defined as above. 
Sixth Hypothesis. Skill conditions produce higher expectancies for success than chance conditions for children at preoperational and formal operational stages of cognitive development.

Prediction. Under skill conditions, defined by game, children in the preoperational group and children in the formal operational group, defined by grade, will show higher average expectancy for success than under chance conditions, measured by the total number of chips bet per game.

Subjects

Subjects were 100 four-to twelve-year old boys and girls selected randomly from prekindergarten screening and grade five of a middle income metropolitan Boston public school system.

Interview protocols were obtained from the regular education screening of June, 1987. Interviews were conducted by the examiner (AT) in the position of consulting school psychologist for the cooperating school system. Protocols were used by the school system primarily for educational planning and program evaluation. Validation of all screening procedures was a secondary objective. Data were coded in such a manner that individual children cannot be identified.

Subjects composed of two chronological age groups: (a) group 1, 51 preschool children of ages ranging from 4.3 to 5.8 years $(\underline{M}=5.2)$ and (b) group 2,49 grade five children 
of ages ranging from 10.3 to 12.2 years $(\underline{M}=11.1)$.

Summary statistics on grade, gender and age of subjects are shown in Table 1. Average standard scores for subjects derived from administration of the Peabody Picture Vocabulary Test - Revised are shown in Table 2. 
Table 1

Chronological Ages of Subjects in years

$\underline{\underline{M}}$

$\underline{\text { SD }}$

$\underline{\mathrm{n}}$

Preschool

$\begin{array}{llll}\text { Boys } & 5.21 & .38 & 23 \\ \text { Girls } & 5.19 & .26 & 28\end{array}$

Grade 5

$\begin{array}{llll}\text { Boys } & 11.20 & .42 & 25 \\ \text { Girls } & 11.10 & .43 & 24\end{array}$


Table 2

standard scores of subjects on the Peabody picture Vocabulary Test - Revised

$\underline{M} \quad \underline{\mathrm{SD}} \quad \underline{\mathrm{n}}$

Preschool

$\begin{array}{lrrr}\text { Boys } & 104.33 & 14.8 & 23 \\ \text { Girls } & 101.37 & 8.8 & 28\end{array}$

Grade 5

$\begin{array}{lrrr}\text { Boys } & 106.00 & 8.2 & 25 \\ \text { Girls } & 103.62 & 12.3 & 24\end{array}$


Phase 1: An Interview Validation Study

The purpose of Phase 1 was to evaluate the psychometric properties of the Bialer Locus of Control Scale and the Piaget-type measure of chance conceptualization in consideration of evidence that the perceived competence dimension of locus of control is directly related to age and the perceived contingency dimension of locus of control is inversely related to age. The study replicates and extends prior research on developmental aspects of locus of control by considering a wider range of grade levels and the two measures of causal attribution.

\section{Method}

Subjects

The 100 randomly selected elementary school children were assigned to first administration conditions in counterbalanced order. Thirty-four preschool children and 33 grade five children were randomly chosen for a retest of the Bialer Locus of Control Scale (Bialer,1961) and the Piaget-type measure.

Materials

Materials included the Bialer Locus of Control Questionnaire (Bialer, 1961), the Piaget-type measure of chance conceptualization adapted for this study, and Form L of the Peabody Picture Vocabulary Test-Revised (Dunn, 1981). 
Bialer Locus of Control Questionnaire. The Bialer Locus of Control Questionnaire (Bialer, 1961) was used as a competence-based measure of internal locus of control.

Bialer (1961) developed the questionnaire from the James-Phares (James, 1957) adult scale of internal-external control. As indicated previously, the scale consists of 23 verbally administered questions in an agree/disagree format which are scored in the internal direction. Eighteen items are scored internal upon a "Yes" response, and five items are scored internal upon a "No" response. A sample of the Bialer Locus of Control Questionnaire may be reviewed in Appendix A.

In view of the numerous items scored "Yes," the plausibility that the scale is affected by response set bias should be questioned. However, based on a sample of 189 moderately retarded adults, Bialer (Gozali \& Bialer, 1968) obtained insignificant correlations between scores on the Children's Locus of Control questionnaire and two independent measures of response set bias or social desirability, the True-False form of the Children's Social Desirability Questionnaire (Crandall, Katkovsky, \& Crandall, 1965) and the Couch and Keniston Agreement Response Scale (cited in Gozali \& Bialer, 1968).

In the same study, Bialer (Gozali \& Bialer, 1968) investigated the stability of the scale. Test-retest scores, obtained using a seven day interval $(\underline{\mathbb{N}}=60)$, yielded a reliability coefficient of .84 (Pearson). Also, 
an alternate-forms reliability coefficient of .67 was obtained when scores on the children's Locus of Control Questionnaire were correlated with a reverse version of the questionnaire $(\underline{\mathrm{N}}=36)$.

Battle and Rotter (1963) found some evidence for the validity of the Bialer Locus of Control scale in a procedure which called for the administration of a line matching task, a projective instrument, and the Bialer scale to 80 sixth- and eighth-grade children. Battle and Rotter obtained a significant correlation (-.42) between the Children's Picture Test of Internal-External Control originated by Battle, and the Bialer Locus of Control Questionnaire. The Children's Picture Test is scored in the external direction accounting for the negative relationship.

Battle and Rotter also found that the Bialer scale correlated significantly with the number of unusual responses to reinforcement $(\underline{r}=-.47)$ on an adaptation of a line matching task developed by James (1957). Subjects scoring low-internal on the Bialer scale raised expectancies after failure and lowered them after success more than subjects scoring high-internal.

piaget-type measure. This apparatus is similar to a device used by Piaget and Inhelder (1975) to measure chance conceptualization in children. Materials consist of a rectangular tray $(27 \mathrm{~cm} \times 40 \mathrm{~cm})$ which rests on a crosswise axle, allowing it to seesaw. In the starting 
position, the box is inclined toward one of its ends. A group of three red marbles and a group of three black marbles are arranged across its width at the lower end.

A Trajectory Drawing Form $(22 \times 28 \mathrm{~cm}$ white bond paper) which represents the outline of the apparatus is provided as a measure of random mixture and reversibility. A sample Trajectory Drawing Form is duplicated in Appendix B. The form shows the original positions of the marbles, in color, with blank positions outlined to indicate possible final arrangements of the marbles. Children are provided with red and black marking pens to color the paths of marbles from original to final locations.

Peabody Picture Vocabulary Test - Revised. The Peabody Picture Vocabulary Test-Revised, Form L (Dunn, 1981) was used as a verbally based measure of mental age equivalent. The PPVT- $R$ is an individually administered, norm-referenced, power test of hearing vocabulary which was standardized on a sample of 5,028 persons including 4,200 children and 828 adults.

Form L contains 5 training items, followed by 175 test items arranged in order of increasing difficulty. Each item has four simple, black-and-white illustrations arranged in a multiple-choice format.

Psychometric properties reported in the Manual for the PPVT- $R$, Forms $L$ and $M$, include internal consistency and alternate-forms reliability (Dunn, 1981). Split-half correlations were calculated for all 5,028 subjects (age 
$21 / 2$ through 40 years) in the standardization sample. Internal consistency estimates corrected by the spearmanBrown formula ranged from .67 to .88 for Form L (median .80 ), and from .61 to .86 for Form M (median .81).

Alternate-forms reliabilities were derived from the counterbalanced administration of Forms $L$ and $M$ to 642 subjects selected from the standardization sample to represent each age group from 2 1/2 through 18 years. These coefficients of equivalence for raw scores based on immediate retest ranged from .73 to .91 (median .82). For PPVT-R standard scores, coefficients of equivalence ranged from .71 to .89 (median .79).

Delayed retest alternate-forms reliabilities, which were obtained after an interval of from 9 to 31 days, were reported on 962 subjects (age $21 / 2$ to 18) selected from the standardization sample to represent each age, sex, occupation, and race. These coefficients of stability, based on delayed retest, ranged from .52 to .90 (median .78) for raw scores and from .54 to .90 (median .77) for standard scores.

No criterion-related validity data were described in the Manual. However, Dunn (1981) determined the equivalence of scores on the 1981 Form $L$ of the PPVT-R with the 1959 Form $A$ of the PPVT in a study of 1,849 children, ages 3 through 18 years, separate from the standardization group. The median PPVT-R standard score equivalent was 7 to 8 points lower than the median PPVT 
IQ, with a range of from 5 to 17 points lower. Design

Results were evaluated by intercorrelations. KuderRichardson Formula 20 was applied to Bialer responses to determine the internal consistency of the scale and product-moment correlations were used for measures of relationship. Counterbalancing the order of presentation of all measures was employed to minimize sequence effects. The Bialer and Piaget-type scales were analyzed by testretest. The Piaget-type measure was scored by two independent raters.

\section{Procedure}

Bialer Locus of Control Questionnaire. Children were administered the Bialer Questionnaire in accordance with Bialer's instructions (Bialer, 1961) described in Appendix A.

Piaget-type measure. The same male experimenter (AT) conducted all performance sessions. Each child, was seen individually, and seated at a table opposite the experimenter. A few minutes were spent putting the child at ease and the child was invited to play a game using the following pretested instructions:

See these marbles lined up in the box. Put your finger on the red ones. Now put your finger on the black ones. The box can be tipped so that the marbles will move to the other side and back again. (The experimenter demonstrates how the box moves while 
holding the marbles in place.)

Now watch what happens when the gate is opened and the box is tipped. (The experimenter tips the box.) See how some of the marbles are in different positions. (The child is given five seconds to examine the marbles, then the experimenter returns the marbles to their original positions.)

Here are two colored pens, a red one and a black one, you are to draw on this paper how the marbles will line up when they return to the starting gate. (The child is given two pens and a trajectory drawing form with the original positions of red and black marbles colored in two groups.)

Use this form to show me if the red ones will stay on one side of the box and the black ones on the other side, or if they will get mixed up. Draw how the marbles will line up when they return to this side of the box. (The child completes the drawing and is subsequently asked two questions) .

What will happen if the box is moved many

times? Will the marbles get back to where they started?

The Piaget-type game of random mixture and reversibility was scored in the contingency or reversibility direction, that is, subjects who drew the marbles returning in a systematic way scored higher. The scoring procedures, which were developed for the current 
investigation, are described in Appendix C.

Mental age. Children were administered the Peabody Picture Vocabulary Test (Dunn, 1981) in accordance with instructions in the manual in order to obtain mental age equivalency and IQ scores.

\section{Results}

First administration total sample $(\underline{N}=100)$ intercorrelations across grade levels between the Peabody Picture Vocabulary Test-Revised (PPVT-R), the Bialer Locus of Control Questionnaire and the Piaget-type measure of Randomness and Reversibility were $.41(\underline{p}<.001)$ and -.69 $(\underline{p}<.001)$, respectively. Pearson coefficients between these measures and chronological age are presented in Table 3 .

\section{First Hypothesis}

Competence-based internality, measured by the Bialer scale, was directly related to chronological age (.43) and increased verbal ability on the PPVT-R (.41). The correlation obtained in the current study between Bialer and PPVT scores is intermediary between the value (.26) reported by Penk (1969) who examined average children, and the value (.56) reported by Bialer (1961) who examined average and intellectually subaverage children.

Second Hypothesis

Contingency-based internality, measured by the Piaget-type scale, showed strong and inverse relationships to chronological age $(-.69)$ and verbal ability $(-.69)$. The 
Table 3

Intercorrelations Between Chronological Age, Verbal

Ability and Locus of Control Measures for Elementary

school Children

$\begin{array}{llll}\text { Measure } & 2 & 3 & 4\end{array}$

Preschool and fifth grade children $(\underline{\mathrm{N}}=100)$

1. Chronological Age

$.94 *$

$.43 *$

$-.69 *$

2. PPVT-R

$.41 * \quad-.69 *$

3. Bialer

$-.19$

4. Piaget-type

$* \underline{p}<.001$ 
intercorrelation of the two locus of control scales was insignificant indicating that they are measuring different dimensions of generalized expectancies.

Table 4 lists the mean, standard deviation, median, mode, skew, and kurtosis of each measure of age and locus of control for the groups. The total sample size consists of 51 preschool and 49 grade five students. The frequency distributions of the measures are generally symmetrical and rather flat.

The Kuder-Richardson Formula 20 coefficient for the Bialer total sample $(\underline{\mathrm{N}}=100)$ was .58 . KR-20 estimates for each grade level ranged from .55 for preschool $(\underline{n}=51)$ to .47 for grade $5(\underline{n}=49)$. These estimates are more consistent than values obtained by Halpin and ottinger (1983) in a recent study of Bialer scale reliabilities. Their estimates ranged from .32 for grade 4 to .57 for grade 6 .

Stability coefficients of the locus of control measures for total sample, preschool and grade five are presented in Tables 5, 6 and 7, respectively.

Total retest sample $(\underline{n}=67)$ reliability was .68 ( $\underline{1}$ <.001) for the Bialer scale. Gozali and Bialer (1968) obtained a higher retest reliability coefficient (.84) for the Bialer scale in a study of 60 intellectually subaverage adolescents and adults ranging in ages from 16 to 30. Total retest sample reliability for the piagettype measure $(\underline{\underline{n}}=64)$ was $.83(\underline{p}<.001)$. 
Table 4

Chronological Age, Verbal Ability and Locus of Control scores for Elementary school children

$$
\text { Total Sample }(\underline{\mathrm{N}}=100)
$$

Measure

Mean SD Median Mode Skew Kurtosis

\begin{tabular}{lrrrrrr}
\hline CA & 8.00 & 3.00 & 5.67 & 10.67 & .12 & -1.96 \\
PPVT-R & 8.46 & 3.45 & 7.50 & 4.58 & .24 & -1.37 \\
Bialer & 13.54 & 3.28 & 14.00 & 12.00 & -.28 & .04 \\
Piaget-type & 6.13 & 4.18 & 5.00 & 13.00 & .52 & -1.12 \\
\hline
\end{tabular}

Preschool $(\underline{\mathrm{n}}=51)$

Measure Mean SD Median Mode Skew Kurtosis

\begin{tabular}{lrrrrrr}
\hline CA & 5.20 & 3.32 & 5.17 & 5.08 & -.37 & -.25 \\
PPVT-R & 5.43 & 1.04 & 5.41 & 4.58 & .39 & .33 \\
Bialer & 12.18 & 3.17 & 12.00 & 14.00 & -.31 & .04 \\
Piaget-type & 8.82 & 3.86 & 9.50 & 13.00 & -.38 & -1.17 \\
\hline
\end{tabular}

$$
\text { Grade Five }(\underline{n}=49)
$$

Measure Mean SD Median Mode Skew Kurtosis

$\begin{array}{lrrrrrr}\text { CA } & 11.11 & .41 & 11.08 & 10.67 & .71 & .37 \\ \text { PPVT-R } & 11.84 & 1.42 & 11.33 & 11.00 & 1.10 & .66 \\ \text { Bialer } & 15.04 & 2.70 & 15.00 & 12.00 & .11 & -1.07 \\ \text { Piaget-type } & 3.13 & 1.85 & 3.00 & 3.00 & .78 & .33\end{array}$


Table 5

Stability coefficients of the Bialer and

Piaget-type Measures

\section{Measure}

Condition

Bialer

Piaget-type

First Testing

$\underline{\text { n }}$

$\underline{\mathbf{M}}$

$\underline{\text { SD }}$

Second Testing

$\underline{\mathrm{n}}$

$\underline{\mathbf{M}}$

$\underline{\mathrm{SD}}$

$\underline{\mathbf{r}}$

$\star p<<.001$
67

13.49

3.35

67

13.60

3.12

$.68 *$
64

5.98

4.43

64

6.34

4.02

$.83 *$ 
Table 6

stability coefficients of the Bialer and Piaget-type Measures for Preschool Children

Measure

condition

Bialer

Piaget-type

First Testing

$\underline{\mathrm{n}}$

$\underline{\text { M }}$

$\underline{S D}$

Second Testing

$\underline{n}$

$\underline{\mathbf{M}}$

$\underline{S D}$

$\underline{\underline{r}}$

SD

(1)
34

12.00

3.23

34

12.15

3.05

$.50 *$
32

9.00

4.28 $\underline{1}$

$* \mathrm{p}<.01 \quad * * \mathrm{p}<.001$ 
Table 7

Stability coefficients of the Bialer and Piaget-type Measures for Grade Five Children

\section{Measure}

Condition

Bialer

Piaget-type

First Testing

$\underline{\mathrm{n}}$

$\underline{\mathbf{M}}$

$\underline{\mathrm{SD}}$

Second Testing

$\underline{\mathrm{n}}$

$\underline{\mathbf{M}}$

$\underline{\text { SD }}$

$\underline{r}$

p $<.05$
33

15.03

2.77

33

15.09

2.44

$.73 * *$
32

2.97

1.70
32

3.47

1.72

$.43 *$ 
Bialer scale retest reliabilities ranged from .50 $(\underline{p}<.01)$ for preschool children $(\underline{\mathrm{n}}=34)$ to $.73(\underline{\mathrm{p}}<.001)$ for grade five children $(\underline{\mathrm{n}}=33)$. Piaget-type measure retest reliabilities ranged from .73 ( $\underline{p}<.001)$ for preschool children $(\underline{n}=32)$ to $.43(\underline{p}<.05)$ for grade five children $(\underline{n}=32)$.

Rater reliability for total sample $(\underline{N}=100)$ first administration of the Piaget-type measure was .97 ( $p<$ .001) (Pearson) and gives further evidence of the reliability of the measure. Correlations ranged from .96 $(\underline{p}<.001)$ for the preschool sample $(\underline{\mathrm{n}}=51)$ to .84 ( $\underline{\mathrm{p}}<$ $.001)$ for the grade five sample $(\underline{\mathrm{n}}=49)$. Drawings of grade five children were more complex than drawings of preschool children and this is reflected in somewhat lower consistency of scoring for grade five drawings by raters. 
Phase 2: A Multifactor Repeated Measures study

The purpose of Phase 2 of the study was to demonstrate the effects of perceived competence and perceived contingency within the same set of experimental procedures and to assess the developmental effects of these variables on locus of control. Two groups were exposed to the same stimuli and were distinguished in terms of response to feedback conditions.

\section{Method}

\section{Subjects}

Subjects were the same 100 elementary school children who participated in Phase 1 of the study. The children were assigned to experimental conditions in counterbalanced order.

\section{Materials}

Chance game. These materials are similar to those used by Weisz (1980). They consist of 80 poker chips, two decks each of eight white cards $(7.5 \times 13 \mathrm{~cm})$, half with green spots on one side, half with yellow spots one side, and a small container $(6 \times 10 \mathrm{~cm})$ for chips won.

skill game. Ten Muller-Lyer type illusion designs (cited in Woodworth \& Schlosberg, 1964) of varying lengths with outward pointing angles at their ends are identified by numbers ranging from 1 to 10. They consist of vertically placed black lines which are $.30 \mathrm{~cm}$ in thickness and range in length from 23 to $13 \mathrm{~cm}$. They are drawn on 22 x $28 \mathrm{~cm}$ white bond paper. A sample Muller-Lyer type 
reference design is presented in Appendix D.

Eight of the ten reference designs are devised in such a manner that they match (within $.15 \mathrm{~cm}$ ) the lengths of eight vertical stimulus lines with inward angles drawn on $22 \times 28$ white bond paper and placed on a clipboard in prearranged order. A sample Muller-Lyer type stimulus design is presented in Appendix $\mathrm{E}$.

The Muller-Lyer designs were used in order to make the actual differences between line lengths more ambiguous, allowing for control of reinforcements by the experimenter. Pretesting of the task with adult volunteers indicated that two additional, non-matching, reference lines were needed to confound some subjects who attempted to use a process of elimination to win the game. The materials also included 80 poker chips.

\section{Procedure}

Chance game. Eight white cards are spread out in front of the child, four with a yellow spot on one side, and four with a green spot on one side. The child is asked to count out four yellows, and four greens. The child is asked to assist the experimenter in mixing the cards. While lining up 80 poker chips in front of the child, the experimenter says:

For this game, you must draw yellow cards from the deck in order to win. Each time that you play, you can bet up to ten chips. When you get a yellow card, you will win the chips that you bet in that game and 
we will place them in this container. When you draw a green card, you will loose the chips that you bet in that game. You will get to bet eight times. If you win enough chips, you will win a prize.

Remember, the more sure you are that you will be correct, the more chips that you should bet.

I have found that success at this game is entirely a matter of luck.

winnings are controlled by using two eight-card decks, one deck with yellow and green spots in a prearranged order. After betting eight times, all children are given a prize. The response measure is the number of chips bet in each trial.

skill game. Ten Muller-Lyer reference designs of varying length and outward angles are placed on a display board. The child is seated comfortably at an uncluttered table approximately 3 meters away from the display board. The child is asked to count the numbers, one through ten, which accompany the designs on the board.

Eight stimulus designs with inward pointing angles are consecutively shown to the child in prearranged order, one design for each trial. The instructions to the child are made as identical as possible to instructions for the chance game except for emphasis on attributing success to a skill situation. The experimenter says:

I have eight designs here on this clip board. For this game, you are to tell me which lines on the clip 
board are the same length as the lines on the display board when the differences between the lines are small.

Each time that you play, you can bet up to 10 chips. When you are correct, you will win the chips that you bet in that game. When you are incorrect, you will loose the chips that you bet in that game. You will get to bet eight times. If you win enough chips, you will win a prize.

Remember, the more sure you are that you will be correct, the more chips that you should bet.

I have found that some kids have a special skill at this game and usually do better than others. Winnings are controlled by feedback from the experimenter. After the eighth trial, all children are given a prize. The response measure is the number of chips bet for each trial.

Betting technique. The betting technique which is used as the dependent measure of expectancy for success for the games was developed by Castaneda (cited in Phares, 1957 and James, 1957). It provides subjects with objects of value which are used to bet on performance. The amount of the bet is considered an objective and quantified representation of the expectancy value on a Likert-type scale ranging from 1 to 10.

Rotter, Fitzgerald, and Joyce (1954) supported the construct validity of the betting technique for adults ( $\underline{N}=$ 
120) in a comparison of the task with three different verbal measures of expectancy. Although the betting or behavioral technique produced significantly higher absolute expectancy ratings, mean ratings were highly correlated (.99) with the verbal measure in which subjects were asked to rate, on a ten-point scale, their probability of success on six trials. Rotter et al. concluded that the two methods measure the same construct.

\section{Results}

The expectancy measure was the number of chips bet per trial (range from 1 to 10). Data were analyzed by a $2 \times 2$ x 2 x 8 (Grade $x$ Gender x Game $x$ Trial) fixed effects analysis of variance with repeated measures on the last two variables. Table 8 shows the ANOVA summary. Grade and gender were between-subjects variables. Game and trial were within-subjects variables.

Means and standard deviations of the expectancy data for all conditions are presented in Tables 9 and 10. Significant main effects were found for grade, $\underline{F}(1,96)=$ $10.91, \underline{\mathrm{p}}<.001 ;$ game, $\underline{\mathrm{F}}(1,96)=36.25, \underline{\mathrm{p}}<.001$; and trial, $\underline{F}(7,672=2.82, \underline{p}<.01$. Significant interactions were found for Game $x$ Trial, $\underline{F}(7,672)=5.46, \underline{p}<.001$; and Grade $\times$ Game x Trial, $\underline{F}(7,672)=3.08, \underline{p}<.01$. No significant main effects or interactions were found for the variable of gender.

As predicted, the main effect for grade is consistent with the decreasing expectancy of success as a function of 
Table 8

Summary of Analysis of Variance for Expectancy Scores

Source Sum of Squares df Mean Square $\underline{F}$

Between subjects

$\begin{array}{lrrrc}\text { Grade (GR) } & 577.04 & 1 & 577.04 & 10.91 * * \\ \text { Gender (GN) } & 34.13 & 1 & 34.13 & .65 \\ \text { GR x GN } & 5.70 & 1 & 5.70 & .11 \\ \text { Sub. w. groups } & 5075.52 & 96 & 52.87 & \end{array}$

Within subjects

Game (GM)

281.28

GR $\times$ GM

GN $\times$ GM

GR $\times$ GN $\times$ GM

GM $x$ sub. w. groups

Trial ( $\mathrm{T}$ )

GR $\times \mathrm{T}$

GN $\times$ T

GR $\times$ GN $\times$ T

T $\mathrm{x}$ sub. w. groups

GM $\times$ T

GR $\times$ GM $\times$ T

GN $\times$ GM $\times$ T

GR $\times$ GN $\times$ GM $\times \mathrm{T}$

GM $\times$ T $\times$ sub. w. groups
5.74

11.51

26.07

744.96

85.25

36.54

$18 \cdot 14$

39.94

2901.49

141.74

80.01

18.49

19.73

2494.12
$1 \quad 281.28 \quad 36.25$ * *

1

5.74

.74

$1 \quad 11.48$

1.48

$1 \quad 26.07$

3.36

96

7.76

7

12.18

2.82 *

5.22

1.21

2. 59

.60

5.71

1.32

672

4.32

7

20.25

$5.46 * *$

7

11.43

$3.08 *$

7

2.64

.71

2.82

.76

$\star \mathrm{p}<.01 . \quad * * \mathrm{p}<.001$. 
Table 9

Expectancy Scores for Preschool Children by Gender,

Game, and Trial

\section{Trial}

$\begin{array}{llllllllll}\text { Group } & 1 & 2 & 3 & 4 & 5 & 6 & 7 & 8\end{array}$

Skill

Male

$\begin{array}{lllllllll}\text { M } & 5.52 & 6.22 & 6.78 & 6.48 & 7.52 & 6.26 & 6.26 & 6.00\end{array}$

$\begin{array}{lllllllll}\text { SD } & 3.16 & 3.15 & 2.81 & 3.06 & 2.87 & 3.40 & 2.85 & 3.30\end{array}$

Female

$\begin{array}{lllllllll}\text { M } & 5.39 & 5.11 & 5.50 & 5.35 & 6.21 & 6.11 & 6.14 & 6.43\end{array}$

$\begin{array}{lllllllll}\underline{S D} & 3.34 & 2.64 & 2.66 & 2.70 & 2.60 & 2.66 & 2.66 & 2.73\end{array}$

Chance

Male

$\begin{array}{lllllllll}\text { M } & 5.26 & 4.70 & 5.74 & 5.17 & 5.43 & 4.91 & 5.52 & 5.13\end{array}$

$\begin{array}{lllllllll}\underline{\mathrm{SD}} & 3.51 & 3.44 & 3.57 & 3.11 & 3.65 & 3.40 & 3.41 & 3.43\end{array}$

Female

$\begin{array}{lllllllll}M & 5.14 & 5.29 & 5.04 & 5.68 & 5.39 & 6.11 & 5.68 & 5.57\end{array}$

$\begin{array}{lllllllll}\underline{\mathrm{SD}} & 3.17 & 2.80 & 3.09 & 3.01 & 2.94 & 2.57 & 2.84 & 2.83\end{array}$

Note. Preschool sample was $\underline{n}=23$ for males and $\underline{n}=28$ for females. 
Table 10

Expectancy Scores for Grade Five Children by Gender,

Game and Trial

\section{Trial}

$\begin{array}{lllllllll}\text { Group } & 1 & 2 & 3 & 4 & 5 & 6 & 7 & 8\end{array}$

Skill

Male

$\begin{array}{llllllllll}\text { M } & 4.56 & 5.36 & 6.04 & 4.36 & 5.32 & 4.80 & 4.36 & 6.48\end{array}$

$\begin{array}{lllllllll}\text { SD } & 1.64 & 2.14 & 2.51 & 1.66 & 2.46 & 1.96 & 2.46 & 2.29\end{array}$

Female

$\begin{array}{lllllllll}\underline{\mathrm{M}} & 4.29 & 4.50 & 5.46 & 4.67 & 5.54 & 4.79 & 3.75 & 5.67 \\ \underline{\mathrm{SD}} & 1.60 & 1.69 & 2.00 & 1.83 & 2.08 & 2.48 & 1.57 & 2.65\end{array}$

Chance

Male

$\begin{array}{lllllllll}\text { M } & 4.76 & 3.84 & 3.08 & 4.24 & 4.12 & 4.20 & 5.32 & 4.72\end{array}$

$\begin{array}{lllllllll}\text { SD } & 2.28 & 2.50 & 2.40 & 2.31 & 2.95 & 2.41 & 2.23 & 3.33\end{array}$

Female

$\begin{array}{lllllllll}\text { M } & 3.71 & 3.67 & 3.12 & 3.67 & 3.71 & 3.79 & 4.62 & 4.00\end{array}$

$\begin{array}{lllllllll}\mathrm{SD} & 1.55 & 2.41 & 2.59 & 1.68 & 2.25 & 2.45 & 2.72 & 3.09\end{array}$

Note. Grade five sample was $\underline{\underline{n}}=25$ for males and $\underline{\underline{n}}=24$ for females. 
grade. The right column of Table 11 shows higher overall expectancy for success by preschool children $(\underline{M}=5.71)$ compared to grade five children $(\underline{M}=4.52)$ collapsed across gender, game, and trial.

The main effect for game implies that children in the skill condition $(\underline{\mathrm{M}}=5.53)$ have higher expectancy for success than children in the chance condition $(\underline{M}=4.70)$. The right column of Table 12 shows the game effect collapsed across grade, gender, and trial.

The main effect for trial implies that changes in expectancy are a result of the reinforcement schedule. Table 13 shows that trials 3, 4, 5, 6, and 8 vary monotonically with outcome when trials are collapsed across grade, gender, and game.

Furthermore, inspection of the means associated with the Game $x$ Trial interaction collapsed across grade and gender (shown in Table 14), and simple effects tests, indicate that the game condition difference occurred between skill and chance conditions on trials 2, 3, 5, and 8. The four significant $\underline{F}$ values, in respective order, are $\underline{F}(1,768)=4.59, \underline{p}<.05 ; \underline{F}(1,768)=16.52, \underline{p}<.001 ;$ $\underline{F}(1,768)=12.46, \underline{p}<.001 ;$ and $\underline{F}(1,768)=9.71, \underline{p}<.01$.

Table 15 presents the mean expectancy scores and standard deviations associated with the Grade $x$ Game $x$ Trial interaction collapsed across the nonsignificant variable of gender. This significant interaction supports the prediction that children's expectancies for success 
Table 11

Expectancy Scores of Elemenary School Children by Grade

Game

Group

Skill

Chance

Overall

Preschool

M

6.05

5.37

5.71

$\underline{\mathrm{SD}}$

2.90

3.17

3.03

Grade Five

$\begin{array}{llll}\text { M } & 5.00 & 4.04 & 4.52 \\ \text { SD } & 2.01 & 2.44 & 2.23\end{array}$


Table 12

Expectancy scores of Elementary school children by Game

\section{Grade}

Game

Preschool

Grade Five

Overall

Skill

$\underline{\mathbf{M}}$

6.05

5.00

5.53

$\underline{\text { SD }}$

2.90

2.01

2.45

Chance

$\begin{array}{llll}\text { M } & 5.37 & 4.04 & 4.70 \\ \text { SD } & 3.17 & 2.44 & 2.80\end{array}$


Table 13

Expectancy Scores for Elementary School Children by Trial

\begin{tabular}{|c|c|c|c|c|c|c|c|c|}
\hline & \multicolumn{8}{|c|}{ Trial } \\
\hline & 1 & 2 & 3 & 4 & 5 & 6 & 7 & 8 \\
\hline \multicolumn{9}{|l|}{ Type of } \\
\hline Reinforcement & & + & + & - & + & - & - & + \\
\hline$\underline{\mathbf{M}}$ & 4.84 & 4.84 & 5.08 & 4.96 & 5.40 & 5.15 & 5.22 & 5.52 \\
\hline$\underline{\mathrm{SD}}$ & 2.68 & 2.67 & 2.82 & 2.58 & 2.83 & 2.77 & 2.72 & 2.95 \\
\hline
\end{tabular}


Table 14

Expectancy Scores for Elementary school Children by

Game and Trial

Trial

$\begin{array}{lllllllll}1 & 2 & 3 & 4 & 5 & 6 & 7 & 8\end{array}$

\section{Game}

skill

$\begin{array}{lllllllll}\text { M } & 4.95 & 5.28 & 5.92 & 5.20 & 6.13 & 5.50 & 5.15 & 6.16 \\ \text { SD } & 2.60 & 2.50 & 2.53 & 2.48 & 2.70 & 2.71 & 2.64 & 2.73\end{array}$

Chance

$\begin{array}{llllllllll}\text { M } & 4.73 & 4.40 & 4.25 & 4.72 & 4.68 & 4.80 & 5.30 & 4.88 \\ \text { SD } & 2.77 & 2.84 & 3.12 & 2.68 & 3.03 & 2.82 & 2.81 & 3.17\end{array}$


Table 15

Expectancy Scores for Elementary School Children by Grade, Game and Trial

Trial

$\begin{array}{llllllllll}\text { Group } & 1 & 2 & 3 & 4 & 5 & 6 & 7 & 8\end{array}$

Preschool $(\underline{\mathrm{n}}=51)$

Skill

$\begin{array}{lllllllll}\underline{M} & 5.45 & 5.61 & 6.08 & 5.86 & 6.80 & 6.18 & 6.20 & 6.24 \\ \text { SD } & 3.23 & 2.91 & 2.78 & 2.89 & 2.78 & 2.99 & 2.72 & 3.00\end{array}$

Chance

$\begin{array}{lllllllll}\underline{\mathrm{M}} & 5.20 & 5.02 & 5.35 & 5.45 & 5.41 & 5.57 & 5.61 & 5.37 \\ \underline{\mathrm{SD}} & 3.29 & 3.09 & 3.30 & 3.03 & 3.25 & 3.00 & 3.08 & 3.09\end{array}$

Grade Five $(\underline{n}=49)$

Skill

$\begin{array}{lllllllll}M & 4.43 & 4.94 & 5.75 & 4.51 & 5.43 & 4.80 & 4.06 & 6.08\end{array}$

$\begin{array}{lllllllll}\text { SD } & 1.61 & 1.96 & 2.27 & 1.73 & 2.26 & 2.21 & 2.07 & 2.48\end{array}$

Chance

$\begin{array}{lllllllll}\text { M } & 4.24 & 3.75 & 3.10 & 3.96 & 3.92 & 4.00 & 4.98 & 4.37 \\ \text { SD } & 2.01 & 2.43 & 2.49 & 2.03 & 2.61 & 2.41 & 2.48 & 3.21\end{array}$


vary as a function of grade, game, and outcome. The means associated with the Grade $x$ Game $x$ Trial interaction are represented graphically in Figure 1 for fifth grade children and in Figure 2 for preschool children. Third Hypothesis

The third hypothesis stated that, for children at the stage of formal operations, skill conditions are related to the perception of internal locus of control based on the salient dimension of competency. It was predicted that, under skill conditions, formal operations children, represented by the grade five group, will show a pattern of usual expectancy shifts in response to reinforcement, that is, increments after success and decrements after failure.

The third hypothesis involved comparisons of mean expectancies across trials of grade five children at the skill game condition.

Means and standard deviations of the game by trial interaction for grade five are shown in the lower portion of Table 15 and graphically in Figure 1. The simple effects test on the Game $\mathrm{x}$ Trial interaction for grade five was sigificant, $\underline{F}(7,672)=7.65, \underline{p}<.001$; and the simple, simple effects test on the skill trials for grade five was significant, $\underline{F}(7,2688)=5.83, \underline{p}<.001$.

Inspection of Figure 1 and comparisons of the eight skill trial means of grade 5 children using Tukey's HSD test $(\underline{p}<.05)$ (Glass \& Stanley, 1970; Winer, 1971) revealed a pattern of usual expectancy shifts. Under skill 


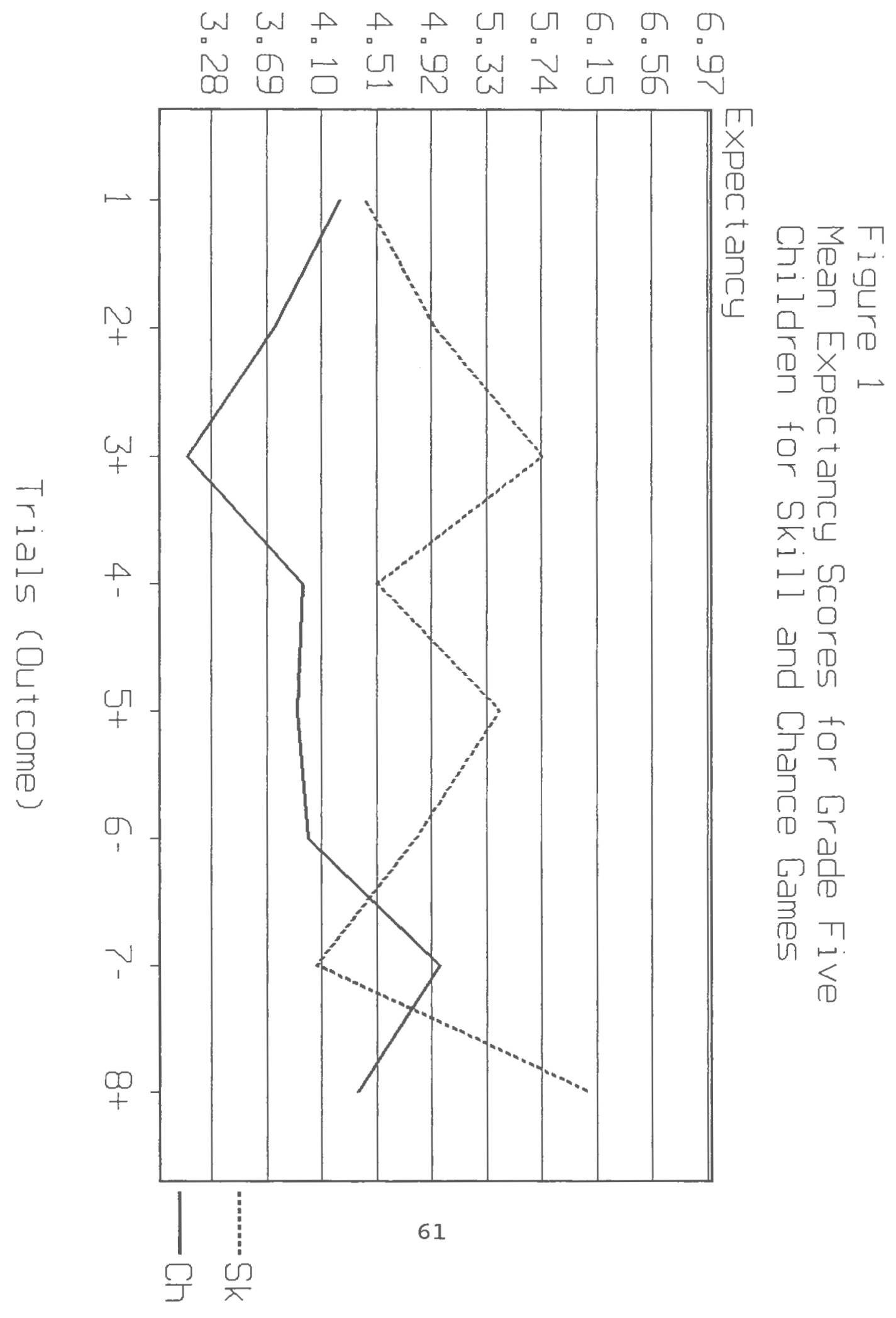




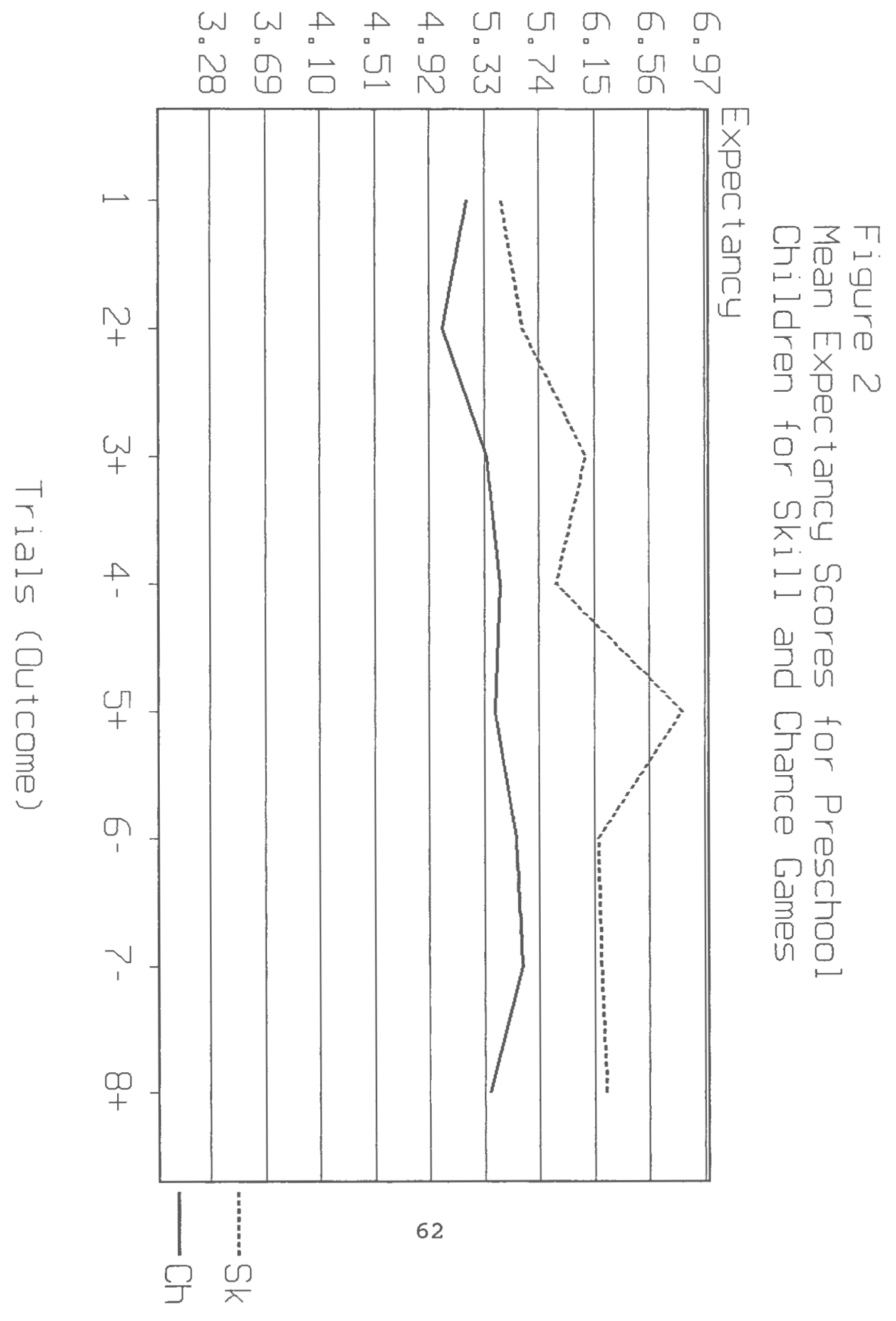


conditions, expectancies of grade five children varied monotonically with outcome history, indicating that they used the feedback accumatively in forming their expectancies. Specifically, a significant increment in mean expectancy was found between trials 1 and 3 following success; a significant decrement was found between trials 3 and 4 following failure; a significant decrement was found between trials 5 and 7 following failure; and a significant increment was found between trials 7 and 8 following success.

\section{Fourth Hypothesis}

The fourth hypothesis stated that, for children at the stage of formal operations, chance conditions are related to the perception of external locus of control based on a mature understanding of probability. Using this reasoning, it was predicted that, under chance conditions, formal operations children, represented by the grade five group, will show a pattern of unusual expectancy shifts in response to reinforcement, that is, decrements after success and increments after failure. This pattern of expectancies is the inverse of the pattern of expectancies predicted for the skill game.

The fourth hypothesis involved comparisons of mean expectancies across trials of grade five children at the chance game condition.

Means and standard deviations of chance trials for grade five are shown at the bottom of Table 15 and 
graphically in Figure 1. The simple, simple effects test on the chance trials for grade five was significant, $\underline{F}$ ( 7 , $2688)=3.52, \underline{p}<.001$.

Inspection of Figure 1 and comparisons of the eight chance trial means of grade 5 children using Tukey's HSD test $(\underline{p}<.05)$ (Glass \& Stanley, 1970; Winer, 1971) revealed a pattern of unusual expectancy shifts. Under chance conditions, the expectancies of grade five children varied monotonically with outcome history, and inversely with skill expectancies, indicating that they used the feedback accumatively in forming their expectancies. Specifically, a significant decrement in mean expectancy was found between trials 1 and 3 following success, and a significant increment was found between trials 3 and 7 following failure.

\section{Fifth Hypothesis}

The fifth hypothesis stated that children at the preoperational stage of development impose subjective order or contingency on both skill and chance situations. For these children, contingency is the salient variable for both skill and chance games. This hypothesis lead to a pair of predictions.

Firstly, it was predicted that preoperational children, represented by the preschool group, will show an essentially flat profile of expectancies in response to success/failure feedback in both skill and chance games. In other words, it was predicted that outcome feedback 
would not be used accumatively by preschoolers in forming expectancies.

The means associated with the Game $x$ Trial interaction for preschool children are shown in the upper portion of Table 15 and graphically in Figure 2. The simple effects test on the game by trial interaction at preschool was not significant, $\underline{F}(7,672)=0.80, \underline{p}>.05$, indicating that outcome feedback was not used accumatively in forming expectancies under either skill or chance conditions.

secondly, it was predicted that preschool children will exhibit higher expectancies for success than grade five children in both skill and chance games. This prediction involved comparisons of skill means across grades and of chance means across grades (shown in Table 15).

Figure 3 represents the skill game means for grades five and preschool. Consistent with this prediction, the simple effects test on the grade by trial interaction for the skill game was significant, $\underline{F}(7,1344)=2.64, \underline{p}<.01$. Simple, simple effects tests on the skill game means indicated that the grade condition difference occurred between preschool and grade five on trials 1, 4, 5, 6, and 7. The significant $\underline{F}$ values, in respective order, are $\underline{F}(1,1536)=5.10, \underline{p}<.05 ; \underline{F}(1,1536)=8.33, \underline{p}<.01 ;$ $\underline{F}(1,1536)=8.99, \underline{p}<.01 ; \underline{F}(1,1536)=8.77, \underline{p}<.01$, and $\underline{F}(1,1536)=18.75, \underline{p}<.001$. 


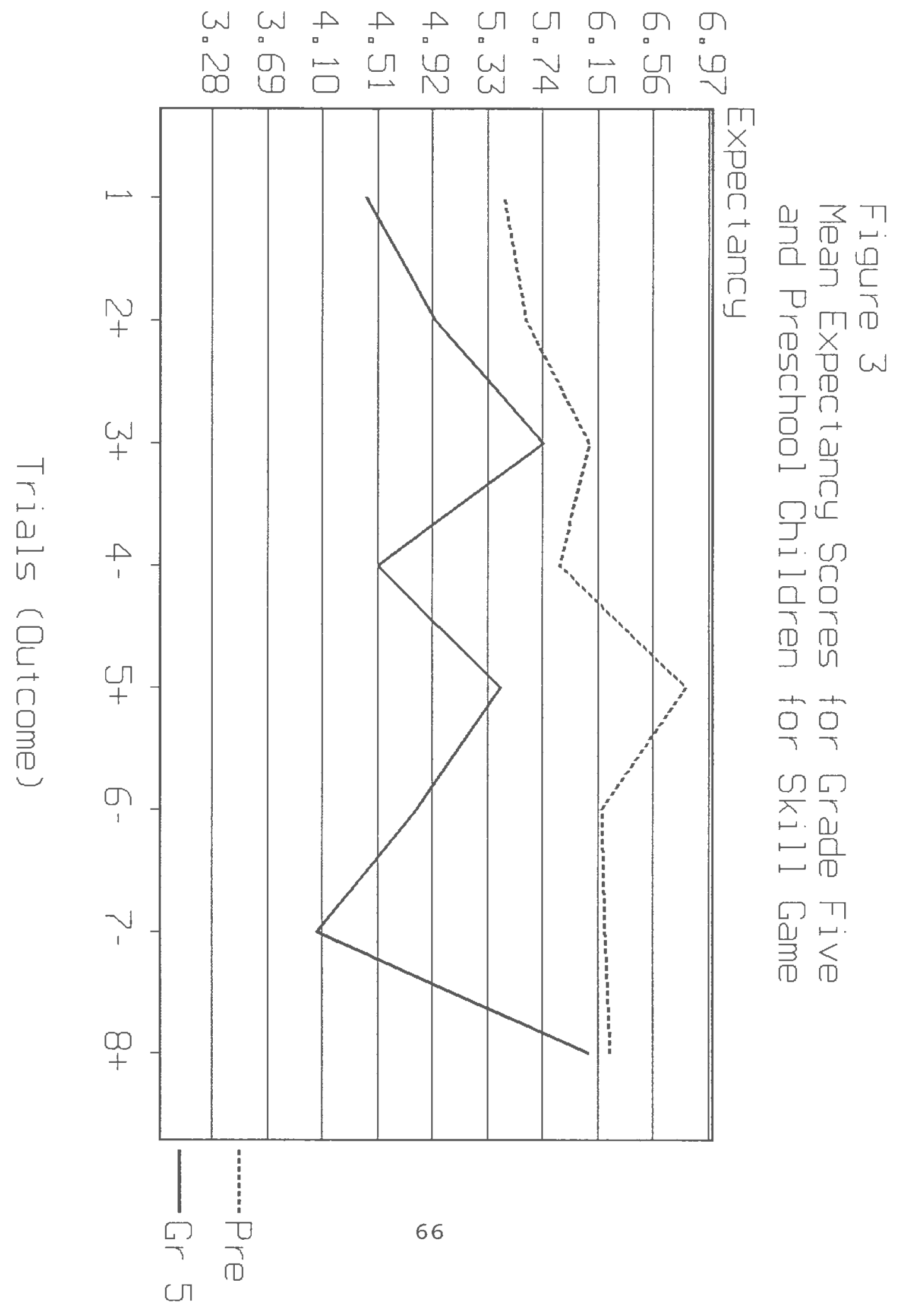


Figure 4 shows the chance game means for grades five and preschool. Simple, simple effects tests on the chance game means of the grade by trial interaction indicated that the grade condition difference occurred between preschool and grade five on trials $1,2,3,4,5,6$, and 8 . The significant $\underline{F}$ values, in respective order, are $\underline{F}(1,1536)=$ $4.45, \underline{\mathrm{p}}<.05 ; \underline{\mathrm{F}}(1,1536)=7.10, \underline{\mathrm{p}}<.01 ; \underline{\mathrm{F}}(1,1536)=$ $20.06, \underline{\mathrm{p}}<.001 ; \underline{\mathrm{F}}(1,1536)=22.46, \underline{\mathrm{p}}<.001, \underline{\mathrm{F}}(1,1536)=$ $9.67, \underline{\mathrm{p}}<.01, \underline{\mathrm{F}}(1,1536)=10.61, \underline{\mathrm{p}}<.01$, and $\underline{F}(1,1536)=4.93, \underline{p}<.05$. Sixth Hypothesis

The sixth hypothesis stated that skill conditions are related to higher expectancies for success than chance conditions for all children. It was predicted that both preschool and grade five children will show higher expectancies for success in the skill game compared to the chance game. The sixth hypothesis involved comparisons of skill trial means and chance trial means separately for the preschool and grade five groups.

The skill and chance trial means for grade five, which are presented in Table 15, are represented graphically in Figure 1. Simple effects tests indicated that the game condition difference for grade five children occurred between skill and chance games on trials $2,3,5,7$, and 8 . The five significant $\underline{F}$ values, in respective order, are $\underline{F}(1,1536)=8.13, \underline{p}<.01 ; \underline{F}(1,1536)=40.86, \underline{p}<.001 ;$ $\underline{F}(1,1536)=13.24, \underline{p}<.001$; and $\underline{F}(1,1536)=4.90$, 


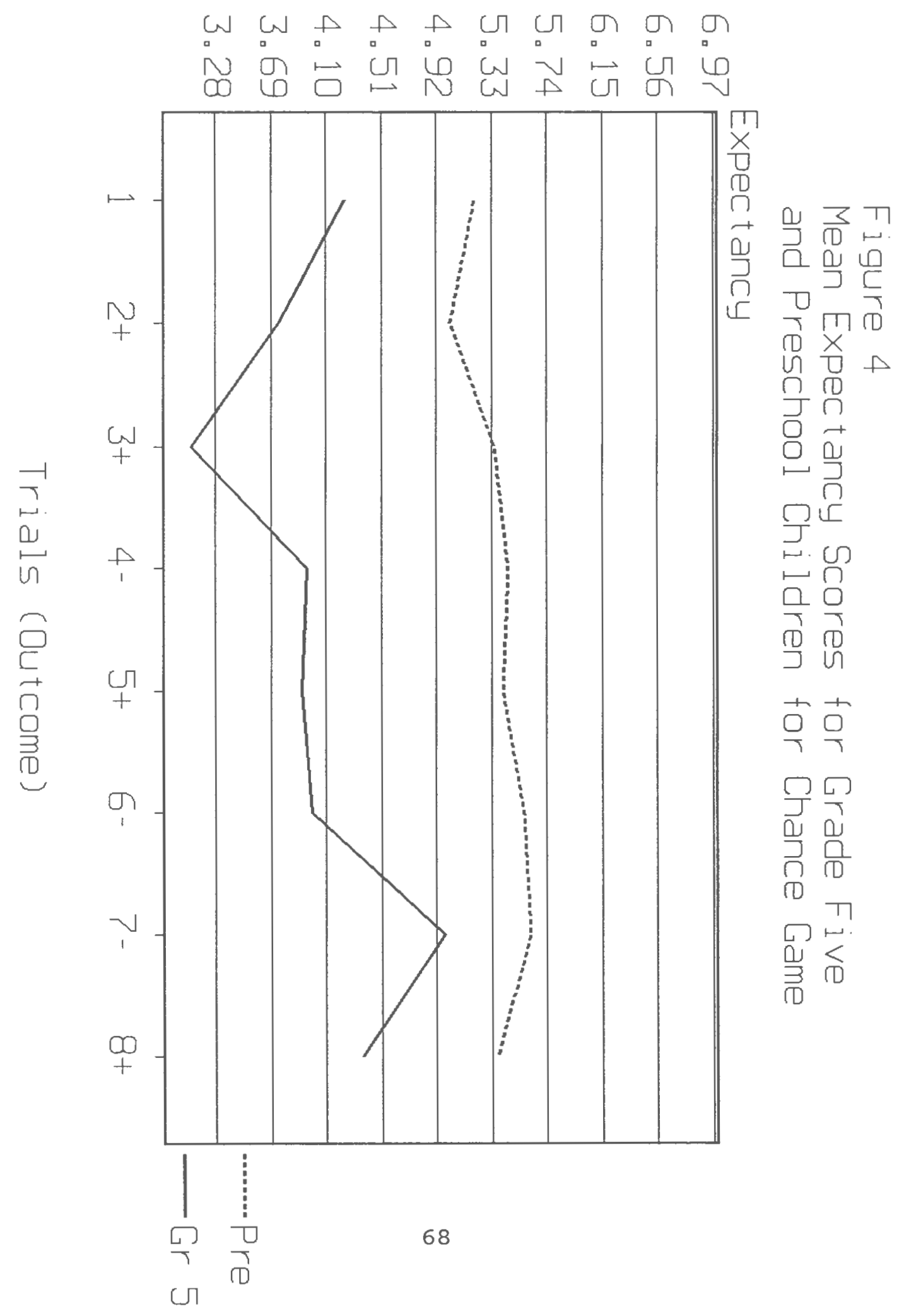


$\underline{\mathrm{p}}<.05, \underline{\mathrm{F}}(1,1536)=17.06, \underline{\mathrm{p}}<.001$.

The skill and chance trial means for preschool are presented in Table 15, and represented graphically in Figure 2. Simple effects tests indicated that the game condition difference occurred between skill and chance games on trials 5, and 8 for preschool. The two significant $\underline{F}$ values, in respective order, are $\underline{F}(1,1536)=$ $11.71, \underline{\mathrm{p}}<.001$ and $\underline{\mathrm{F}}(1,1536)=4.50, \underline{\mathrm{p}}<.05$. 
Discussion

Phase 1

Phase 1 of the current inquiry represented an independent replication and extension of investigations by Bialer (1961) and Penk (1969) regarding the relationship between competence-based internal locus of control and age.

Bialer (1961) posited that mental age, rather than chronological age, was the more relevant variable related to the inclination among children to perceive internal locus of control.

Data from the current inquiry, which were obtained from a cognitively average subject sample, did not support Bialer's (1961) assertion that mental age is the salient factor related to competence-based internal control.

Results of Phase 1 supported the first hypothesis that perceived competence is directly related to chronological age in children. It was found that older children responded more frequently in the perceived competence direction of locus of control on the Children's Locus of Control Questionnaire (Bialer, 1961), than younger children.

The age related increments in perceived competence shown by elementary school children are consistent with the prediction that, as they grow older, children become increasingly more aware that competence influences their environment.

The current findings are consistent with those of Penk 
(1969) regarding the progressive relationship between competence-based locus of control and chronological age, and extend the convergent validity of Bialer's scale to a preschool population. This is some evidence that older children are higher in the generalized expectancy that reinforcement occurs as a result of their own competence. The data are also consistent with evidence from Milgram (1971) who found age related progressions in locus of control using the Bialer Scale (1961) with 80 elementary school children in grades one, four, seven, and ten.

Milgram (1971) concluded that age related increments in internal locus of control imply that children become increasingly competent in manipulating their environment and increasingly aware that their own behavior is instrumental in producing desired outcomes and avoiding undesired outcomes.

The second hypothesis of Phase 1 was concerned with the inverse relationship between contingency-based locus of control and age, which was first delineated by Weisz (1980, 1981) and Weisz and Stipek (1982). These researchers based their hypothesis of locus of control upon the Piagetian explanation of chance conceptualization (Flavell, 1963; Piaget \& Inhelder, 1975).

Results of Phase 1 showed that younger children responded more frequently in the perceived contingency direction on the Piaget-type scale of chance conceptualization than older children. The finding of age 
related decrements in perceived contingency supports the prediction that young children make more judgments which attribute causal dependency to random events than older children. Preschool children seem to have more difficulty than their older counterparts identifying the noncontingent nature of chance controlled outcomes.

A case can be made for the developmental character of the contingency variable studied here, and for the qualitative immaturity of the cognitive system of the preschool child compared to the fifth grade child. The strong negative relationship between chronological age and perceived contingency lends additional support to the Piagetian theory of chance conceptualization. It also provides evidence for the convergent validity and utility of measuring the contingency construct with the Piaget-type instrument developed for the current study.

In general, the findings of Phase 1 support the multidimensional view of locus of control, which was proposed by Pargament, Sullivan, Tyler, and Steele (1982) in a study of relationships between a variety of locus of control and individual competence measures. These researchers found low-order positive correlations between internal control and measures of competence, and low-order negative correlations between measures of control by chance and competence.

The data also sustain speculation by Weisz and Stipek (1982) that, while adults may use various combinations of 
both competence and contingency information to make judgments about whether they can exercise control, preoperational children may find it difficult to use both dimensions concurrently. They may rely exclusively on the more salient control relevant dimension of contingency. In addition to substantive issues, Phase 1 examined the psychometric properties of the Children's Locus of Control Questionnaire (Bialer, 1961) and the Piaget-type measure of chance conceptualization. Discriminate validity of the two scales was supported by their low and insignificant intercorrelation indicating that they were measuring different dimensions of control expectancies.

Internal consistency reliabilities for the Bialer scale were moderate and consistent for preschool and grade five children suggesting that both age groups responded to the questionnaire in a systematic manner.

stability estimates both across and within grade levels for the Bialer and Piaget-type scales were moderate in value and somewhat variable.

Test-retest reliabilities for the Bialer scale were significant for preschool and grade five children although the stability of responses was higher for the grade five children.

Bialer (1961) used his scale extensively with intellectually subaverage subjects of a mental age equivalent of 3 years, 10 months. However, the question was raised whether children as chronologically young as 
preschool age understand the content of the Bialer scale even when read to them by the examiner. In the Milgram (1971) study mentioned above, test-retest correlations for the Bialer scale at grades one and seven were not significant. The presence of a significant test-retest correlation for preschool and grade five in the current study may be taken as some evidence of understanding by the children of the items in the Bialer scale. Nevertheless, the lower test-retest correlation obtained for the younger age group recommends some caution in this interpretation.

Test-retest reliabilities for the Piaget-type scale were significant for both groups. However, in this comparison, stability coefficients were higher for the preschool children than for the grade five children. Inspection of the test protocols supports the interpretation of generally greater sophistication, defined by evidence of relatively mature chance conceptualization, but higher variability in the drawings of older children. This finding is consistent with Piagetian theory (Piaget \& Inhelder, 1975) which would predict that the 4 to 5 year old children $(\underline{\mathrm{M}}=5.2)$ in the younger comparison group are solidly within the preoperational range (4 to 7 years), and are thus expected to lack an internalized standard of randomness. Whereas, 10 to 12 year old children $(\underline{M}=11.1)$ in the older comparison group are beginning the stage of formal operational thought in which 
the concept of randomness first appears but may not yet be consolidated.

Rater reliability for the Piaget-type scale was, obviously, adequate. There were some responses on fifth grade protocols which were problematic, but these anomalies did not affect total scores enough to jeopardize reliability, and most responses were clearly either random or systematic.

The scoring guidelines, which were developed for the Piaget-type scale, established adequate conventions for determining the ambiguous responses, and also provided an expanded operational definition of contingency, defined by this method.

The results of this correlational phase of the current study represented some exploratory evidence that contingency-based locus of control and competence-based locus of control can be operationalized reliably in a developmental context. Phase 2 of the study was an attempt to apply these constructs in an experimental investigation using different operational procedures and methods. Phase $\underline{2}$

The various significant interactions of Phase 2 indicated that expectancies vary as a function of age, situational cue, and outcome. Gender differences emerged in neither the preschool nor the grade five groups. While preschoolers started with, and maintained, higher expectancies, fifth grader's expectancies changed more in 
response to success and failure. The results revealed that, within this experiment, perceived competence and perceived contingency influenced expectancies for success.

Analysis of the data supported the third hypothesis that skill conditions are related to the perception of internal locus of control in children at the cognitive stage of formal operations. This hypothesis was based on combined evidence from Rotter's $(1966,1975)$ theory of locus of control, Piaget's explanation of chance conceptualization (Flavell, 1963; Piaget \& Inhelder, 1975), and results of Phase 1 of the current investigation. The expectancies of grade five children varied systematically with outcome history in the skill game. These children showed the predicted pattern of usual expectancy shifts, which consisted of accumulatively higher expectancies following success and accumulatively lower expectancies following failure. Findings suggested that cognitively mature children are more likely to conclude that outcome feedback is determined by the internal control factor of competence when they are in the skill situation. This finding extends, to fifth grade children, Rotter's hypothesis of locus of control, which was derived from studies with adults (James \& Rotter, 1958; Phares, 1957; Rotter, Liverant, \& Crowne, 1961).

In regard to the fourth hypothesis, results supported that chance conditions are related to the perception of external locus of control in children at the cognitive 
stage of formal operations. Grade five children showed a systematic pattern of unusual expectancy shifts in the chance game. Their expectancies varied inversely with outcome history, that is, they showed accumulatively lower expectancies after success and accumulatively higher expectancies after failure.

This conclusion is consistent with Rotter's (James \& Rotter, 1958) prediction that mature subjects will show more unusual shifts in behavior in chance situations, operationally defined as "a raise in expectancy following negative reinforcement or a decrease in expectancy following positive reinforcement" (p. 398). However, the current investigation was more successful than previous research with adult volunteers (James \& Rotter, 1958; Phares, 1957; Rotter, Liverant, \& Crowne, 1961) in showing evidence for unusual expectancy shifts or the gambler's fallacy.

The fifth hypothesis was supported that preoperational children impose subjective order on both skill and chance situations. This hypothesis developed out of the work of Weisz (1981) which was based on Piaget's explanation of chance conceptualization (Flavell, 1963; Piaget \& Inhelder, 1975). It was also consistent with evidence from Phase 1 of the current study which suggested that young children are likely to over estimate contingency because of an immature understanding of probability and randomness. Statistical analysis of Phase 2 data confirmed the 
first prediction of hypothesis five that preschool children do not use outcome feedback systematically in forming their expectancies. Evidence of stable expectancies (insignificant shifts) in both games suggested that preoperational children are inclined to overlook outcome feedback in forming expectancies, and to rely on subjective judgments which exaggerate contingency.

Results correspond to findings from Weisz (1981) who determined that young children predict certain minimal outcomes (baselines) under conditions of skill and chance, apparently disregarding past outcomes in their estimates of future performance.

This conclusion is supported by Parsons and Ruble (1977), who examined the development of achievement-related expectancies in children. Based on models of attribution and cognitive developmental theory, these researchers determined that success/failure experiences have a more systematic effect on the expectancies of school-age children than on the expectancies of preschoolers.

In addition, Siegler and Liebert (1974) reported similar findings in an experimental investigation of outcome regularity and age on the causal judgments of kindergarten and third grade children. Evidence was consistent with Piagetian theory. While outcome regularity in a sequence of learning trials influenced the causal statements of third grade children, it did not influence kindergarten children who persisted in nonconservation 
judgments with apparent disregard for outcomes.

The patterns of stable responses across trials shown by preschool children in the current study imply a cognitive mediational explanation of development and the theory that young children operate by different cognitive rules than adults and older children.

Results of Phase 2 supported the second prediction stemming from hypothesis five that preschool children show higher expectancies for success than grade five children. Preschool children demonstrated higher expectancies in both games than their older counterparts. This finding is compatible with the general decline with grade in the over estimate of contingency observed in Phase $I$ of the current study, and observations of Piaget (Piaget \& Inhelder, 1975), and Weisz (1981).

In particular, Piaget (Flavell, 1963) reasoned that, in the preoperational period from about age 3 or 4 to age 7, young children's causal attributions retain some of the egocentrism of the infant, and consequently they are expected to respond immaturely to the skill versus chance dichotomy by overestimating success.

Parsons and Ruble (1977), in the study described above, also found that younger children report consistently higher expectancies for ability related success. However, these researchers speculated that the observed developmental decline in expectancies with age might reflect: an increase in response to failure by older 
children, a decrease in perceived ability by older children, or an increase in the understanding by older children that it is more socially acceptable to express less rather than more certainty of success.

The interactions observed in the current inquiry are more compatible with the explanation offered by Weisz (1981) than those suggested by Parsons and Ruble (1977). Firstly, grade five children showed a wider range of expectancy in response to both success and failure than preschool children, not merely a greater response to failure. Secondly, evidence from Phase 1 of the current study suggests that awareness of competence actually increases with age. Lastly, significant increases in expectancy of grade five children following success are inconsistent with the social desirability explanation.

The final hypothesis stated that skill conditions induce higher expectancies for success than chance conditions for children. Analysis of the data showed that both preschool and grade five children had higher expectancies for success in the skill game than in the chance game.

The current data extend to children the findings of previous studies on adults using the locus of control model. Specifically, Phares (1957) observed that the mean magnitude of expectancies for success of adults was higher in skill situations than in chance situations; and Rotter, Liverant, and Crowne (1961) concluded that adult volunteers 
verbalized greater expectancy for success in skill situations than in chance situations after the first positive reinforcement and cumulatively.

General Discussion

On a theoretical level, the current findings suggest that all learning may not be accounted for in terms of conditioning processes, but rather that some integration of S-R and cognitive-developmental theories might have heuristic value toward a parsimonious explanation of the data.

The results generally lend support to Piaget's developmental theory of chance conceptualization that actual qualitative differences exist in the causal reasoning of children of different ages. This obviates the continuous, quantitative explanations of cognitive development posited by $S-R$ and social learning theorists.

In the Piagetian framework, cognitive immaturity is associated with young children's tendency to infer causal connections in random situations, while outcome regularity, operationalized in this experiment as the trial factor, would not exert an appreciable influence. The findings of Phase 1 and Phase 2 are consistent with this theory. Indeed, when compared to their fifth grade counterparts, preschool children obtained higher perceived contingency scores on the Piaget-type scale in Phase 1, showed higher expectancy scores on both games in Phase 2, and were not dissuaded from maintaining higher expectancies in response 
to failure on the predetermined outcome schedule (trial effect).

These findings are consistent with observation of Shaklee and Tucker (1979), which indicate that children's judgments of ability become more outcome differentiated with increasing age. These researchers used experimental procedures with preschool and second grade children to explore the role of information-summary skills in making inferences about an actor's ability. Shaklee and Tucker concluded that preschool children do not base their own judgments of ability on performance outcomes across trials.

Other investigators have reported similar response perseveration by young children on models involving hypothesis-testing and discrimination learning. In an experimental study of hypothesis testing, Gholson, Levine, and Phillips (1972) presented kindergarten, second, fourth, sixth grade, and college students with discrimination problems. Kindergarten children almost always persisted in stereotypic repetitions of an hypothesis or rule despite its disconfirmation. For example, kindergarten children often showed stimulus preference in response to outcome feedback. This was reflected in win-stay and lose-stay discriminations similar to those made by preschool children in the current study. Whereas, second grade and older children showed progressively more characteristic hypothesis testing behavior, that is, keeping confirmed 
hypotheses, rejecting disconfirmed hypotheses, as was shown by fifth graders.

Gholson et al. (1972) described the stereotypic repetitions of kindergarten children as learning sets or hypothesis response sets. The subject showing response sets makes systematic choices but these choices are independent of outcome. The hypotheses more characteristic of older children were described as prediction hypotheses. In this case, the subject predicts how rewards will be obtained and acts so as to maximize rewards.

In another developmental study of hypothesis testing behavior using cognitively delayed and average children, Weisz (1977) confirmed that five, seven, and nine year old children show prediction hypotheses most of the time. Furthermore, Ingalls and Dickerson (1969) confirmed that fifth, eighth, tenth grade children and college students solved discrimination learning problems by hypothesis testing and that problem solving efficiency increases with age.

Gholson's (1981) model of hypothesis testing is relevant because it represents an attempt to integrate psychological theories in order to parsimoniously explain developmental differences in problem solving behavior, which are similar to those found in the current investigation.

According to Gholson (1981), problem solving tasks induce the child to develop a set of hypotheses or rules. 
These hypotheses are tested until consistently correct responses are achieved. This process requires an executive or integrative function which reflects underlying cognitive capabilities which change qualitatively with development. The integrative element is designated the cognitive scheme, and it is identified with cognitive operations described by Piaget.

Kendler (1981) posits a related model to account for similar findings of developmental differences in problem solving behavior. The model incorporates connectionist and cognitive paradigms by way of a levels of functioning explanation. Young children are expected to learn single discrimination problems relatively slowly and to show more response sets compared to adults who are expected to solve these problems more rapidly and to show more prediction hypotheses. The inclination to show prediction hypotheses is considered to increase with age, however, the increase will be gradual rather than stepwise as would be implied by Piagetian cognitive theory. The distinction from Gholson is that Kendler argues that response sets are not hypotheses because, by definition, they are not responsive to feedback.

The current investigation lends support to Gholson's view (1981) that response sets are hypotheses. Kindergarten children showed not only stable response patterns to outcome, but also higher expectancies for success than older children regardless of game type. The 
S-R model predicts that expectancies for success gradually increase with age, whereas the Piagetian cognitive model predicts that young children begin with high expectancies for success and gradually lower their expectancies through interactions with the environment.

\section{Future Research}

Seen in its broadest context, the current investigation prompts questions about how human's develop a conception of order in their environment. In the structuralist or organismic model, the task is quickly accomplished, in part, as a consequence of biological predispositions, but initial operating hypotheses used by the child for learning are subsequently revised through maturation and interaction with the environment. In the connectionist model, the infant gradually learns to manipulate the environment, but the rules for learning do not change qualitatively.

Consideration of the sources of evidence in this study lends support to the structuralist view as explicated by Piaget. However, neither model seems sufficient and some integration of structuralist and connectionist paradigms may be fruitful. Such a synthesis of cognitive and $S-R$ principles is not entirely inconsistent with aspects of social learning theory in so far as it accommodates a cognitive mediational approach and conditioning principles. of course, the continuous learning paradigm would likely be modified. 
The development of causal inferences and expectancies for success are important to the solution of all sorts of problems, and the simplification of current psychological theory through the successful integration of structural and connectionist paradigms would be a particularly worthwhile endeavor. 


\section{References}

Bandura, A., Adams, N. E., \& Beyer, J. (1977). Cognitive processes mediating behavior chance. Journal of Personality and Social Psychology, 35, 125-139. Bandura, A., \& Walters, R. H. (1963). Social learning and personality development. New York: Holt, Rinehart, and winston.

Battle, E., \& Rotter, J. B. (1963). Children's feelings of personal control as related to social class and ethnic group. Journal of Personality, 31, 482-490. Bialer, I. (1961). Conceptualization of success and failure in mentally retarded and normal children. Journal of Personality, 29, 303-320. Crandall, v. C., Katkovsky, w., \& Crandall, v. J. (1965). Children's beliefs in their own control of reinforcements in intellectual-academic achievement situations. Child Development, 36, 91-109. Dunn, L. M. (1959). Peabody picture vocabulary test manual. (Tentative ed.) Nashville: George Peabody College for Teachers.

Dunn, L. M. \&, Dunn, L. M. (1981). Peabody picture vocabulary test - revised manual. Circle Pines, Minnesota: American Guidance Service. Flavell, J. H. (1963). The developmental psychology of Jean Piaget. New Jersey: Van Nostrand. Gholson, B. (1981). Commentary on Kendler's review of The cognitive-developmental basis of human learning. 
Developmental Review, 1, 163-170.

Gholson, B., Levine, M., \& Phillips, S. (1972).

Hypotheses, strategies, and stereotypes in

discrimination learning. Journal of Experimental child

Psychology, 13, 423-446.

Glass, G. V., \& Stanley, J. C. (1970). statisical methods

in education and psychology. Englewood Cliffs, New

Jersey: Prentice-Hall.

Gozali, J., \& Bialer, I. (1968). Children's locus of

control scale. American Journal of Mental Deficiency,

72, 622-625.

Halpin, B. M. \&, Ottinger, D. R. (1983). Children's

locus of control scales: A reappraisal of reliability

characteristics. Child Development, 54, 484-487.

Hull, C. L. (1943). Principles of behavior. New York:

Appleton-Century-Crofts.

Hull, C. L. (1952). A behavior system. New Haven: Yale

University Press.

Ingalls, R. P., \& Dickerson, D. J. (1969). Development of

hypothesis behavior in human concept identification.

Developmental Psychology, 1, 707-716.

James, W. H. (1957). Internal versus external control

of reinforcement as a basic variable in learning theory

(Doctoral dissertation, Ohio State University, 1957).

James, W. H., \& Rotter, J. B. (1958). Partial and

$100 \%$ reinforcement under chance and skill conditions.

Journal of Experimental Psychology, 55, 397-403. 
Kendler, T. S. (1981). Development of discrimination learning and problem solving. [Review of the cognitive basis of human learning: studies in hypothesis testing]. Developmental Review, 1, 146-162.

Langer, E. J. (1975). The illusion of control.

Journal of Personality and Social Psychology, 32, 311328 .

Langer, E. J., \& Roth, J. (1975). Heads I win, tails it's chance: the illusion of control as a function of the sequence of outcomes in a purely chance task. Journal of Personality and Social Psychology, 32, 951955.

Lefcourt, H. M. (1982). Locus of control: Current

trends in theory and research (2nd ed.). Hillsdale, New Jersey: Earlbaum.

Milgram, N. A. (1971). Locus of control in negro and white children at four age levels. Psychological Reports, 29, 459-465.

Pargament, K. I., Sullivan, M. S., Tyler, F. B., \& Steele, R. E. (1982). Patterns of attribution of control and individual psychological competence. Psychological Reports, 51, 1243-1252.

Parsons, J. E., \& Ruble, D. N. (1977). The development of achievement-related expectancies. Child Development, 48, 1075-1079.

Penk, W. E. (1969). Age changes and correlates of internal-external locus of control scale. Psychological 
Reports, 25, 856 .

Phares, J. E. (1957). Expectancy changes in skill

and chance situations. Journal of Abnormal and Social

Psychology, 54, 339-342.

Phares, J. E. (1962). Perceptual threshold decrements

as a function of skill and chance expectancies. Journal

of Psychology, 53, 399-407.

Piaget, J., \& Inhelder, B. (1975). The origin of the

idea of chance in children. Norton: New York.

Rosenthal, R., \& Rosnow, R. L. (1975). The Volunteer

subject. New York: Wiley-Interscience.

Rotter, J. B. (1966). Generalized expectancies for

internal versus external control of reinforcement.

Psychological Monographs, 80, (1, Whole No. 609)

Rotter, J. B. (1975). Some problems and misconceptions

related to the construct of internal versus external

control of reinforcement. Journal of consulting and

Clinical Psychology, 43, 56-67.

Rotter, J. B. (1982). The development and applications

of social learning theory. New York: Preager.

Rotter, J. B., Fitzgerald, B. J., \& Joyce, J. N. (1954).

A comparison of some objective measures of expectancy.

Journal of Abnormal and Social Psychology, 49, 111-114.

Rotter, J. B., Liverant, S., \& Crowne, D. P. (1961).

The growth and extinction of expectancies in chance controlled and skilled tasks. Journal of Psychology,

52, 161-177. 
Seigler, R. S., \& Liebert, R. M. (1974). Effects of contiguity, regularity, and age on children's causal inferences. Developmental Psychology, 10, 574-579. Shaklee, H., \& Tucker, D. (1979). Cognitive bases of developmental inferences of ability. Child Development, 50, 904-907.

Skinner, B. F. (1953). Science and human behavior. New York: McMillian.

Weisz, J. R. (1977). A follow-up developmental study of hypothesis behavior among mentally retarded and nonretarded children. Journal of Experimental child Psychology, 24, 108-122.

Weisz, J. R. (1980). Developmental change in perceived control: Recognizing noncontingency in the laboratory and perceiving it in the world. Developmental

Psychology, 16, 385-390.

Weisz, J. R. (1981). Illusory contingency in children at the state fair. Developmental Psychology, 17, 481489 .

Weisz, J. R., \& Stipek, D. J. (1982). Competence, contingency, and the development of perceived control. Human Development, 25, 250-281. Winer, B. J. (1971). Statistical principles in experimental design. New York: McGraw-Hill. Woodworth, R. S., \& Schlosberg, H. (1964). Experimental psychology. New York: Holt, Rinehart and Winston. 
DOB :

DOE :

School

Male/Female

BIALER LOCUS OF CONTROL QUESTIONNAIRE

In the administration of the questionnaire, the subject is asked to respond with "yes" or "no" to each item. The letter "f" indicates that a "yes" response is scored as internal control. The letter "p" signifies that an answer of "no" is scored as internal control. The scale is scored in terms of the total number of responses in the direction of internal control. Examiner circles "Yes" or "No" as indicated.

\section{Instructions}

This is not a test. I am just trying to find out how kids your age think about certain things. I am going to ask you some questions to see how you feel about these things. There are no right answers to these questions. Some kids say "yes" and some say "no." When I ask the question, if you think your answer should be yes, or mostly yes, say "Yes." If you think the answer should be no, or mostly no, say "No." Remember, different children give different answers, and there is no right or wrong answer. Just say "Yes" or "No," depending on how you think the question should be answered. If you want me to repeat a question, ask me. Do you understand? All right, listen carefully, and answer "Yes" or "No."

1p. When somebody gets mad at you, do you usually feel there is nothing you can do about it? Yes. No.

2f. Do you really believe a kid can be whatever he wants to be? Yes. No.

3f. When people are mean to you, could it be because you did something to make them be mean? Yes. No.

$4 \mathrm{f}$. Do you usualiy make up your mind about something without asking someone first? Yes. No.

5f. Can you do anything about what is going to happen tomorrow? Yes. No.

6f. When people are good to you, is it usually because you did something to make them be good? Yes. No.

7f. Can you ever make other people do things you want them to do? Yes. No. 
8f. Do you ever think that kids your age can change things that are happening in the world? Yes. No.

9f. If another child was going to hit you, could you do anything about it? Yes. No.

10f. Can a child your age ever have his own way? Yes. No.

11p. Is it hard for you to know why some people do certain things? Yes. No.

12f. When someone is nice to you, is it because you did the right things? Yes. No.

13f. Can you ever try to be friends with another kid even if he doesn't want to? Yes. No.

14f. Does it ever help to think about what you will be when you grow up? Yes. No.

15f. When someone gets mad at you, can you usually do something to make him your friend again? Yes. No.

16f. Can kids your age ever have anything to say about where they are going to live? Yes. No.

17f. When you get in an argument, is it sometimes your fault? Yes. No.

18p. When nice things happen to you, is it only good luck? Yes. No.

19p. Do you often feel you get punished when you don't deserve it? Yes. No.

20f. Will people usuaily do things for you if you ask them? Yes. No.

21f. Do you believe a kid can usually be whatever he wants to be when he grows up? Yes. No.

22p. When bad things happen to you, is it usually someone else's fault? Yes. No.

23f. Can you ever know for sure why some people do certain things? Yes. No.

Comments : 
Appendix B

Name:

DOB :

$\mathrm{DOE}$ :

School

Male/Female

TRAJECTORY DRAWING FORM

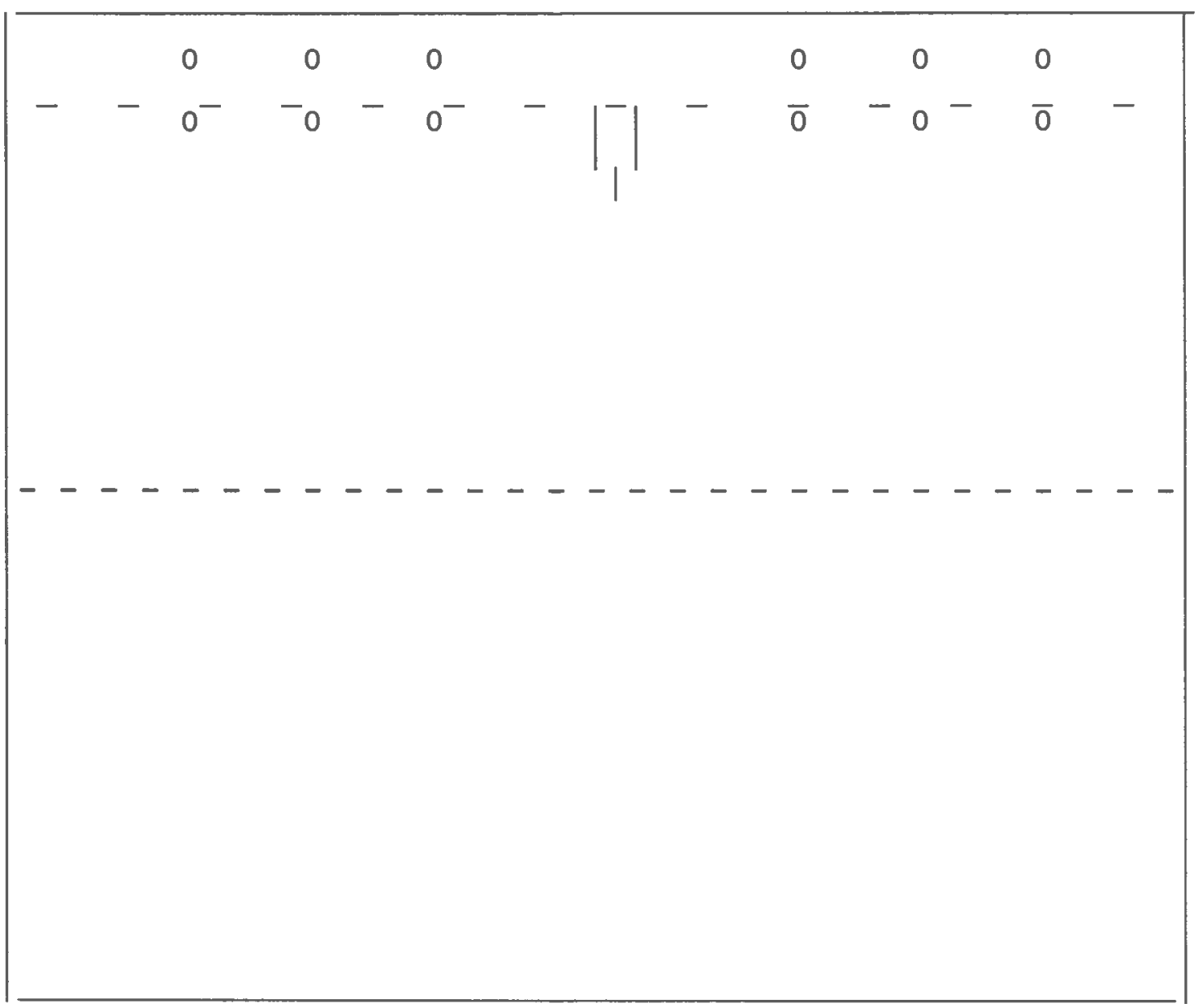

I or $\mathrm{S}$.

What will happen if the box is moved many times? I or $\mathrm{S}$. will the marbles get back to where they started? Yes or No. Comments: 
Appendix C

Scoring Criteria for Children on the Piagetian Game of

Random Mixture and Reversibility

Points

Criteria

1

Spatial Displacement. A marble returns to its original position (marble moves out of its position in a straight line and returns in the same way).

Total spatial displacement. Draws all marbles returning to their original positions.

1

Total verbal displacement. Verbalizes return of all marbles to their original positions.

Replacement A. A colored marble on one side changes places with a marble of a different color on the other side in an equivalent position.

Replacement B. A colored marble on one side changes places with a marble of a different color on the other side in an opposite position.

6

Total replacement. Complete crossing of all the marbles to equivalent positions on the other side.

Failure to cross the midline with three marbles of one color.

Failure to cross midline with all marbles.

All three marbles of one color move one position to right or left consecutively.

All red marbles move one postion toward black side and all black marbles move one position toward red side. 
Appendix D

Muller-Lyer Reference Design

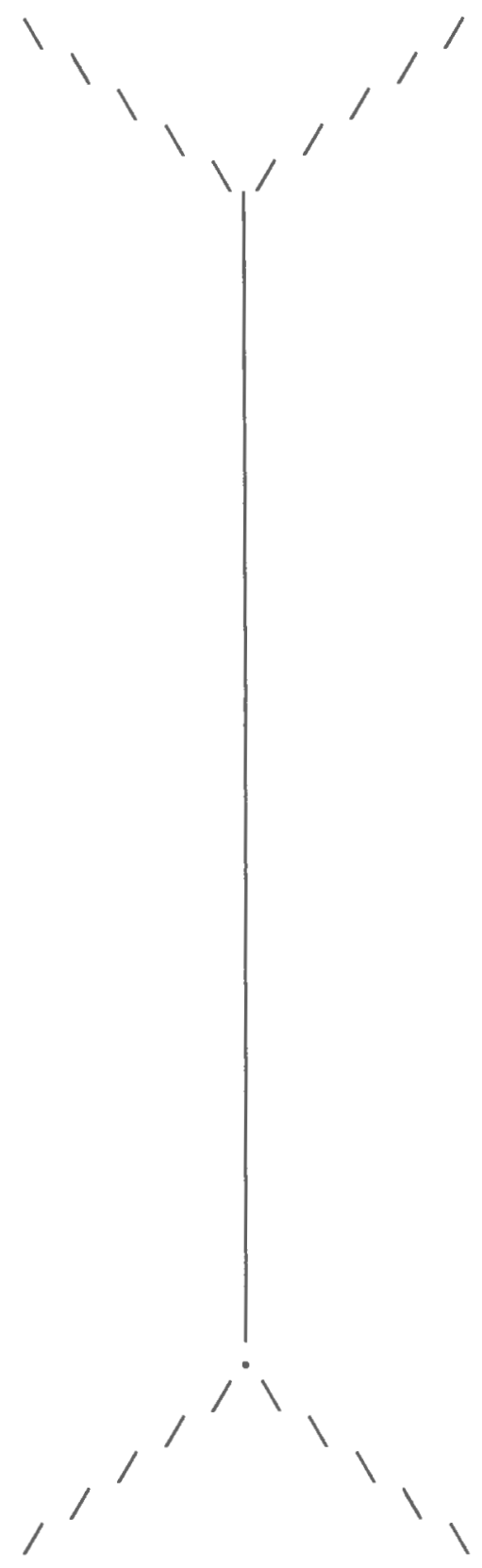




\section{Appendix E}

Muller-Lyer stimulus Design

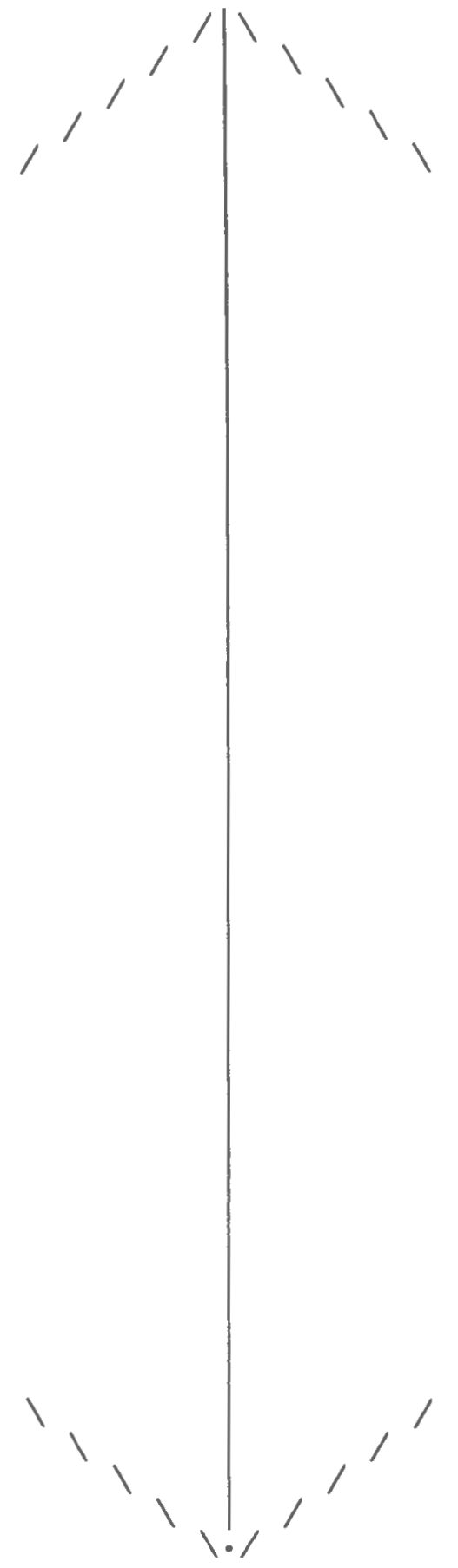




\section{Bibliography}

Bandura, A., Adams, N. E., \& Beyer, J. (1977). Cognitive processes mediating behavior chance. Journal of Personality and Social Psychology, 35, 125-139. Bandura, A., \& Walters, R. H. (1963). Social learning and personality development. New York: Holt, Rinehart, and winston.

Battle, E., \& Rotter, J. B. (1963). Children's feelings of personal control as related to social class and ethnic group. Journal of Personality, 31, 482-490. Bialer, I. (1961). Conceptualization of success and failure in mentally retarded and normal children. Journal of Personality, 29, 303-320.

Crandall, v. C., Katkovsky, W., \& Crandall, V. J. (1965). Children's beliefs in their own control of reinforcements in intellectual-academic achievement situations. Child Development, 36, 91-109. Dunn, L. M. (1959). Peabody picture vocabulary test manual. (Tentative ed.) Nashville: George Peabody College for Teachers.

Dunn, L. M. \&, Dunn, L. M. (1981). Peabody picture vocabulary test - revised manual. Circle Pines, Minnesota: American Guidance Service. Flavell, J. H. (1963). The developmental psychology of

Jean Piaget. New Jersey: Van Nostrand. Gholson, B. (1981). Commentary on Kendler's review of the cognitive-developmental basis of human learning. 
Developmental Review, 1, 163-170.

Gholson, B., Levine, M., \& Phillips, S. (1972).

Hypotheses, strategies, and stereotypes in

discrimination learning. Journal of Experimental child

Psychology, 13, 423-446.

Glass, G. V., \& Stanley, J. C. (1970). Statisical methods

in education and psychology. Englewood Cliffs, New

Jersey: Prentice-Hall.

Gozali, J., \& Bialer, I. (1968). Children's locus of

control scale. American Journal of Mental Deficiency,

72, $622-625$.

Halpin, B. M. \&, Ottinger, D. R. (1983). Children's

locus of control scales: A reappraisal of reliability characteristics. Child Development, 54, 484-487.

Hull, C. L. (1943). Principles of behavior. New York:

Appleton-Century-Crofts.

Hull, C. L. (1952). A behavior system. New Haven: Yale University Press.

Ingalls, R. P., \& Dickerson, D. J. (1969). Development of hypothesis behavior in human concept identification. Developmental Psychology, 1, 707-716.

James, W. H. (1957). Internal versus external control

of reinforcement as a basic variable in learning theory

(Doctoral dissertation, Ohio State University, 1957).

James, W. H., \& Rotter, J. B. (1958). Partial and $100 \%$ reinforcement under chance and skill conditions. Journal of Experimental Psychology, 55, 397-403. 
Kendler, T. S. (1981). Development of discrimination

learning and problem solving. [Review of The cognitive

basis of human learning: Studies in hypothesis testing].

Developmental Review, 1, 146-162.

Langer, E. J. (1975). The illusion of control.

Journal of Personality and Social Psychology, 32, 311328 .

Langer, E. J., \& Roth, J. (1975). Heads I win, tails

it's chance: the illusion of control as a function of

the sequence of outcomes in a purely chance task.

Journal of Personality and Social Psychology, 32, 951955.

Lefcourt, H. M. (1982). Locus of control: Current

trends in theory and research (2nd ed.). Hillsdale, New

Jersey: Earlbaum.

Milgram, N. A. (1971). Locus of control in negro and

white children at four age levels. Psychological

Reports, 29, 459-465.

Pargament, K. I., Sullivan, M. S., Tyler, F. B., \& Steele,

R. E. (1982). Patterns of attribution of control and

individual psychological competence. Psychological

Reports, 51, 1243-1252.

Parsons, J. E., \& Ruble, D. N. (1977). The development of achievement-related expectancies. Child Development, 48, 1075-1079.

Penk, W. E. (1969). Age changes and correlates of internal-external locus of control scale. Psychological 
Reports, 25, 856 .

Phares, J. E. (1957). Expectancy changes in skill

and chance situations. Journal of Abnormal and Social Psychology, 54, 339-342.

Phares, J. E. (1962). Perceptual threshold decrements

as a function of skill and chance expectancies. Journal of Psychology, 53, 399-407.

Piaget, J., \& Inhelder, B. (1975). The origin of the idea of chance in children. Norton: New York.

Rosenthal, R. \& Rosnow, R. L. (1975). The Volunteer subject. New York: Wiley-Interscience. Rotter, J. B. (1966). Generalized expectancies for internal versus external control of reinforcement. Psychological Monographs, 80 , (1, Whole No. 609) Rotter, J. B. (1975). Some problems and misconceptions related to the construct of internal versus external control of reinforcement. Journal of consulting and Clinical psychology, 43, 56-67. Rotter, J. B. (1982). The development and applications of social learning theory. New York: Preager. Rotter, J. B., Fitzgerald, B. J., \& Joyce, J. N. (1954). A comparison of some objective measures of expectancy. Journal of Abnormal and Social Psychology, 49, 111-114. Rotter, J. B., Liverant, S., \& Crowne, D. P. (1961). The growth and extinction of expectancies in chance controlled and skilled tasks. Journal of Psychology, 52, 161-177. 
Seigler, R. S., \& Liebert, R. M. (1974). Effects of contiguity, regularity, and age on children's causal inferences. Developmental Psychology, 10, 574-579. Shaklee, H., \& Tucker, D. (1979). Cognitive bases of developmental inferences of ability. child Development, 50, 904-907.

Skinner, B. F. (1953). Science and human behavior. New York: McMillian.

Weisz, J. R. (1977). A follow-up developmental study of hypothesis behavior among mentally retarded and nonretarded children. Journal of Experimental Child Psychology, 24, 108-122.

Weisz, J. R. (1980). Developmental change in perceived control: Recognizing noncontingency in the laboratory and perceiving it in the world. Developmental Psychology, 16, 385-390. Weisz, J. R. (1981). Illusory contingency in children at the state fair. Developmental Psychology, 17, 481489 .

Weisz, J. R., \& Stipek, D. J. (1982). Competence, contingency, and the development of perceived control. Human Development, 25, 250-281. Winer, B. J. (1971). Statistical principles in experimental design. New York: McGraw-Hill. Woodworth, R. S., \& Schlosberg, H. (1964). Experimental psychology. New York: Holt, Rinehart and Winston. 